\title{
Information transmission within federal fiscal architectures: theory and evidence
}

\author{
Axel Dreher ${ }^{\mathrm{a}}$, Kai Gehring ${ }^{\mathrm{b}}$, Christos Kotsogiannis ${ }^{\mathrm{c}}$ and Silvia Marchesi ${ }^{\mathrm{d}}$ \\ ${ }^{\text {a}}$ Heidelberg University; e-mail: mail@axel-dreher.de \\ bUniversity of Zurich; e-mail: mail@kai-gehring.net \\ cUniversity of Exeter; e-mail: c.kotsogiannis@exeter.ac.uk \\ ${ }^{\mathrm{d}}$ Corresponding author: Department of Economics, University of Milano Bicocca, Piazza \\ dell'Ateneo Nuovo 1, 20126 Milan, Italy; e-mail: silvia.marchesi@unimib.it
}

\begin{abstract}
This paper explores the role of information transmission and misaligned interests across levels of governments in explaining variation in the degree of decentralization across countries. We analyze two alternative policy-decision schemes-'decentralization' and 'centralization' - within a two-sided incomplete information principal-agent framework. The quality of communication depends on the conflict of interests between the government levels and on which government level controls the degree of decentralization. We show that the extent of misaligned interests and the relative importance of local and central government knowledge affect the optimal choice of policydecision schemes. Our empirical analysis confirms that countries' choices depend on the relative importance of private information. In line with our theory the results differ significantly between unitary and federal countries.
\end{abstract}

JEL Classification: H7, H77, D82, D83, C23 


\section{Introduction}

Decentralization, or federalism, allocates responsibilities over policies across different levels of government. With responsibilities over policy divided, the effective transmission of information between government levels is crucial. When the interests of government levels are misaligned, transmission is noisy. In this paper, we identify the optimal degree of decentralization in such a setting. We use a two-sided incomplete information principal-agent framework, in which the transmission of information between local and federal governments is 'soft' and cannot be verified. Whenever the interests of the two government levels differ, the quality of the transmitted information depends on such conflicts of interest, with each level of government rationally expecting the information transmitted by the other level to be distorted (cheap talk game). We compare two types of incentive structures, relative to the quality of the transmitted information: 'centralization' and 'decentralization'. Under centralization the control rights over policies are assigned to the federal government, whereas under decentralization the local governments control policies.

Delegation of decision-making (by either the federal or the local governments) to the other level can be optimal for each government depending on the relative importance of private knowledge. The federal government might opt for delegating policies to the local government in order to be able to fully utilize local knowledge. In equilibrium, the federal government's own information will then only be partially exploited. Under centralization, conversely, the federal government's knowledge will be fully utilized and any deviation from its preferences (due to the local government's reporting bias) will be avoided, at the cost of not fully using local information. Therefore, the optimal allocation of control rights over policies will depend on the relative importance of both levels' information, as well as on the size of the agency bias, which simultaneously affects the amount of information transmitted and the degree of (de-)centralization chosen. What is more, we show not only that 'communication' is important in determining decentralization, but also that institutional differences can explain the different impact that private information of government levels may have. 
We relate to several strands of literature. ${ }^{1}$ The first is the cheap-talk literature building on the seminal work by Crawford and Sobel (1982), who consider the conflict of interests between the owner of a firm and its managers (see, for example, Dessein 2002) or between the CEO and its division managers (as in Harris and Raviv 2005). The second strand of literature emphasizes political incentives (as in, among others, Bordignon et al. 2001, Lockwood 2002, and Kotsogiannis and Schwager 2008) within a decentralized system of governments. Most recently, Kessler (2014) analyzed the public spending decisions of a legislature when legislators engage in truthful information transmission. Assuming that only local governments have an informational advantage, Kessler (2014) finds that misaligned interests between government levels make communication incomplete, which leads to inefficiencies in federal spending decisions. Like Kessler (2014), we analyze challenges of communication in a decentralized economy. However, we focus on communication between a (representative) local and a federal government and the analysis of which level should, optimally, have control over policies when private information is two-sided.

Third, we also relate to the literature on state formation and state development (see Bardhan 2016) as well as to the emerging literature on the structure of unions of political entities (e.g., Alesina et al. 2005 and Gehring and Schneider 2016). Similar to Alesina et al., we consider the trade-off between the benefits from economies of scale and the internalization of externalities versus the costs of combining heterogeneous populations and the limited use of local private information. While this literature endogenizes the boundaries of jurisdictions (Alesina and Spolaore 2003) and the decision to become members of international unions (Alesina et al. 2005), we take the latter as given and endogenize the allocation of policy control between the local and the central level. ${ }^{2}$

Finally, the contribution of this paper is also empirical. ${ }^{3}$ We demonstrate the empirical relevance of

\footnotetext{
${ }^{1}$ Closest to our contribution, Hooghe and Marks (2013) show that even with no heterogeneity of preferences across localities, more populous countries tend to be more decentralized. This is because public good provision depends on soft information, which increases with population size and is difficult to standardize.

${ }^{2}$ Hatfield and Padró i Miquel (2012) propose a positive theory of (partial) decentralization in which decentralization should balance the need for redistribution with the need to avoid highly distortive taxes. They also derive an endogenous federal structure but in their paper federalism is seen as a mechanism for commitment rather than "information disclosure."

${ }^{3}$ Following Oates (1972), a large number of articles have empirically analyzed the determinants of the degree of fiscal decentralization. See Treisman (2006), Bodman et al. (2010), Blume and Voigt (2011), and Sacchi and Salotti (2014) for
} 
our model in a cross-sectional panel analysis of sub-national expenditure decisions over the 19722010 period. The empirical analysis yields results in line with the theoretical prediction of our model. The relative importance of local and federal information as well as the bias between national and sub-national governments helps to explain the degree of decentralization. As predicted, the results differ according to whether the federal or the local governments have the right to decide on the share of subnational expenditures.

\section{Modeling communication between government levels}

The framework relies on the model of Marchesi et al. (2011), which we modify to be applicable to analyze federalism. We distinguish between two regimes according to which government level has the decision power at the beginning of the game (which we call "the principal"), as determined by the constitution of the country.

When the status quo is a unitary country, the federal government is the principal with the final decision rights or veto powers on whether or not to delegate decision-making power to the local governments (e.g., in France, the United Kingdom, and Sweden). A unitary system is one in which decision-making may be decentralized, but final authority rests with the center. Conversely, a federal system (e.g., in the United States, Canada, and Switzerland) disperses authority between "regional governments and a central government in such a way that each kind of government has some activities on which it makes final decisions" (Riker 1987). Most importantly, regions or their representatives can veto constitutional reform. This distinction across regimes will become crucial when taking the theoretical predictions to the data.

To analyze whether the federal (local) government has an incentive to delegate the control of decision-making to the local (federal) governments we focus on the central aspects of the model to derive our hypotheses. For reasons of clarity, all detailed derivations and proofs are delegated

recent contributions.

${ }^{4}$ We do not endogenize who the principal is. This would substantially complicate the analysis but provide no additional insights on the questions we are interested in here. Given that we also work with observed constitutional settings in the empirical part, rather than explaining who is the principal, we leave this extension for future research. 
to the Online Appendix. ${ }^{5}$ The model features two players-federal and local governments—that possess different types of information both required for the optimal design of policies. The optimal policy is defined by $p^{*}=l+f$, where $l$ and $f$ are stochastic variables that proxy for information observed only by the local and, respectively, the federal government. $l$ and $f$ are independently and uniformly distributed on the intervals $[0, L]$ and $[0, F]$, respectively. This captures that the larger the interval $[0, L]([0, F])$, the larger the informational advantage of the local (federal) government. ${ }^{6}$

The local government's superior information over $l$ could, for example, originate from its greater proximity to the 'local business environment' relative to federal government officials or from better knowledge about the risks and opportunities of local investment projects. On the other hand, the federal government's informational advantage, relative to the local government, can originate from several sources. First, country-wide knowledge is accumulated during its activities across the local jurisdictions. Second, the federal government is also likely to possess information with higher informational value about confidential issues such as security or military matters or activities related to the negotiation and implementation of commercial treaties or multilateral activities. Overall, the federal government should therefore be better equipped to take country-wide economic conditions into account. We assume both types of information to be (at least partly) soft.

Events unfold in three stages: allocation of control rights by the principal, communication, and policy implementation. ${ }^{7}$ In the first stage, the principal (federal or local government) either allocates authority over the choice of the policy vector to the agent or retains authority. Centralization refers to the scheme in which the federal government decides on the policy vector, whereas under decentralization control rights are allocated to the local governments. After the first stage of the game,

\footnotetext{
${ }^{5}$ Specifically, Appendix A defines and shows the properties of the communication game, Appendix B derives the ex ante expected losses of the federal and local government, while Appendix $C$ contains proofs of the statements made in Sections 4 and 6 below.

${ }^{6}$ To simplify the analytical setting, we focus on the interaction between a central government and one local government (taken as the 'representative region'), which is assumed not to cover the same population as the central government. This allows us to focus on the implications of information transmission for the choice of centralization vs. decentralization. A model with multiple regions would not provide additional insights to the issues at hand as data to empirically distinguish the degree of decentralization of different regions within a country do not exist.

${ }^{7}$ The analytics feature the case in which both levels of government cannot commit to an incentive-compatible decision rule in which the Revelation Principle applies. This assumption fits in well with the specific relationship between a federal and a local government in which the principal cannot use a standard mechanism to elicit private information from the agent.
} 
the real state of the world is revealed to both players. Then, in the second stage, communication takes place. Under centralization, the local government sends a 'message' to the federal regarding its 'local knowledge'. Upon receiving the message, the federal government updates its beliefs and chooses the policy vector. Under decentralization, the federal government sends a message to the local government concerning its private knowledge. In this case, the local government updates its beliefs and chooses the policy vector. Finally, in the third stage, the chosen government level implements the policy vector and outcomes are realized.

The federal government is assumed to maximize the following objective function

$$
U^{F}=U_{0}^{F}-\left(p-p_{F}^{*}\right)^{2}
$$

where $U^{F}$ decreases with the distance between the actually implemented policy $p$ and the central government's preferred policy $p_{F}^{*}$, and $U_{0}^{F}=U^{F}\left(p_{F}^{*}\right) .{ }^{8}$ The optimal policy of the federal government, $p_{F}^{*}$, differs from the optimal policy from the regional perspective in the sense that $p_{F}^{*}=p^{*}+b_{F}$, with $b_{F}>0$. A possible interpretation of $b_{F}$ is the existence of externalities created by non-cooperative behavior on the part of local governments. When choosing policies, local governments do not internalize the impact of their policy actions on their neighboring localities (for example, when deciding whether or not to provide tertiary education, sharing information potentially useful to national security, regulation, or other public goods). This generates a misalignment of interest between the two levels of government relative to the federal government's country-wide objectives. $^{9}$

Similarly, the local government maximizes

$$
U^{L}=U_{0}^{L}-\left(p-p_{L}^{*}\right)^{2}
$$

\footnotetext{
${ }^{8}$ The utility function (1) can be derived from a more general objective function $\widehat{U}^{F}=W(p)+\gamma W^{R C}(p)$, where $W$ is the region's welfare and $W^{R C}$ measures the welfare of the rest of the country. They both depend on the region's policy $p$. The parameter $\gamma(0 \leq \gamma \leq 1)$ denotes the importance of spillover effects. Taking a Taylor expansion of $\widehat{U}^{F}$ up to the second term, one obtains (1).

${ }^{9}$ Lorz and Willman (2005) introduce a parameter that is similar to $b_{F}$, capturing the importance of externalities in the provision of public goods. More generally, deviations from optimal policy can arise from a number of reasons, such as externalities from sub-national policy decisions, the influence of special interests the federal government takes account of, or personal interests of government members.
} 
which is decreasing in the distance between the implemented policy $p$, and the local government's preferred policy $p_{L^{\prime}}^{*}$ and $U_{0}^{L}=U^{L}\left(p_{L}^{*}\right) .{ }^{10}$ The optimal policy choice from the perspective of the local government deviates from the optimal policy $p^{*}$ by a factor $b_{L}>0$ and is given by $p_{L}^{*}=p^{*}-b_{L}$.

$b_{L}$ proxies for all factors that might lead to a deviation of the local government's preferences from $p^{*}$ : the pressure of local interest groups, re-election concerns, or different time-horizons.

Therefore, the difference in policies that are optimal from the federal and local governments' perspective is given by

$$
p_{F}^{*}-p_{L}^{*}=p^{*}+b_{F}-\left(p^{*}-b_{L}\right)=b_{F}+b_{L}=B
$$

where $B$ represents the extent of the agency problem between the federal and the local government.

\section{Communication equilibria}

\subsection{Federal government as the principal}

As principal, the federal government can choose between centralization or decentralization. Centralization refers to the case in which the federal government has the final choice over policies it wishes to implement in the third stage. It needs to communicate with the local government in the second stage of the game. Opting for centralization, the federal government minimizes the costs of misaligned incentives as it makes full use of its private knowledge. At the same time, it underutilizes the local government's information. Under decentralization the federal government allocates policy decision-making to the local government. In this case, the local government's private knowledge is fully exploited, but the results can deviate from the federal government's optimal policy.

In the communication equilibrium under decentralization the local government obtains only incomplete information about the federal government's knowledge. More specifically, the state space $[0$, $F]$ is partitioned into intervals and the federal government only reveals which interval the true

\footnotetext{
${ }^{10}$ The more general function is: $\widehat{U}^{L}=W(p)+\theta C(p)$, where $C$ are contributions from special interests groups. We assume that $C$ decreases with $p$ and that the parameter $\theta(0 \leq \theta \leq 1)$ denotes the importance of lobbies. Using a Taylor expansion of $\widehat{U}^{L}(p)$ up to the second term, one obtains (2).
} 
value of $f$ belongs to. Therefore, the local government chooses policies by using its own private information and taking the average value of $f$ over the interval $\left(f_{i}, f_{i+1}\right) .{ }^{11}$ The smaller the size of the partition interval, the more informative the federal government's message. We denote the maximum number of intervals, $N(F, B)$, as a function of the bias $B$ and the length of the partition of the federal's knowledge $F$. As one would intuitively expect, the maximum precision of the information transmitted by the federal government decreases with the extent of the agency bias $B$. Put differently, the extent and quality of information transmission depends on the proximity of the preferences of the federal and the local governments: the larger the bias $B$, the less precise and informative cheap talk will be.

Following Crawford and Sobel (1982), the most informative equilibrium-in which the number of intervals $N$ is maximal-always exists and is a focal equilibrium of the communication game. In the focal equilibrium, the federal government's ex ante expected welfare loss increases with the importance of the federal government's private information $F$, since the federal government's private information is not fully exploited under decentralization. ${ }^{12}$

On the other hand, under centralization, information flows from the local to the federal government. The federal government now fully exploits its own information $F$ and chooses its preferred policy vector $p$ in the third stage, after receiving a signal from the local government in the second stage. In this case the federal government sets the policy using its own private information and the average value of $l$ over the interval $\left(l_{i}, l_{i+1}\right)$. As centralization results in an underutilization of the local government's information $L$, the local government's ex ante expected loss is increasing with its informational advantage. ${ }^{13}$

The federal government determines whether or not to retain its control rights over policies by comparing its ex ante expected loss under decentralization with its expected loss under central-

\footnotetext{
${ }^{11}$ Proposition 1 in Appendix A (online) contains more details on the properties of the communication game.

${ }^{12}$ Equations B.1 and B.2 (in Appendix B) show that the federal government's ex ante expected welfare loss increases with the size of the bias $B$ and the ex-ante residual variance of $f\left(\sigma_{f}^{2}\right)$, which is in turn increasing in $F$.

${ }^{13}$ Equations B.4 and B.5 (in Appendix B) show that the federal government's ex ante expected welfare loss increases with the size of the ex-ante residual variance of $l\left(\sigma_{l}^{2}\right)$, which is increasing in $L$.
} 
ization. ${ }^{14}$ Since both are increasing in $F$ (under decentralization) and $L$ (under centralization), we can identify cut-off values of $F$ and $L$ at which the scheme choice switches. The scheme choice, thus, depends on the extent of the conflict of interest $(B)$ and the relative importance of the two players' respective informational advantage $(F, L)$.

Insert Figure 1 here

Figure 1 represents the choice between centralization and decentralization as a function of $L$ and $F$. The threshold $F(L, B)$ is upward sloping and divides the $(L, F)$ plane into two regions (centralization and decentralization) lying below the $45^{\circ}$ line. The federal government will opt for decentralization only if the local government's private information $L$ is (strictly) greater than its own private information $F$ and greater than the threshold level $F(L, B)$. The decentralization region is smaller than the centralization region: the agency bias $B$ requires $L$ to be strictly greater than $F$ in order for decentralization to be optimal. This holds because the loss due to underutilization of the local government's information is compensated for by the elimination of the bias and the full exploitation of the federal government's own private information $L$. Conversely, the federal government always chooses centralization when its private information $F$ is more important than the agent's private information (that is, $F>L$ ). Additionally, it opts for centralization if $F(L, B) \leq F<L$, that is, even when its informational advantage $F$ is smaller than $L$, but greater than the threshold value $F(L, B)$.

In general, the threshold $F(L, B)$ is not monotone in the bias $B$, as an increase in $B$ has both direct and indirect effects. Directly, it increases the agency problem, thus reducing the federal government's incentive to delegate. Indirectly, an increase in $B$ also reduces the equilibrium amount of information transferred by the local to the federal government under centralization, thus making decentralization more attractive. Therefore, an increase in the agent's bias, while making the agent's choice less attractive to the principal, can also decrease the incentives of the agent to communicate its private information in the centralization game more than in the decentralization game.

\footnotetext{
${ }^{14} \mathrm{~A}$ sketch of the proof is reported in Appendix C.
} 
This is a key insight we can derive from the model. The net effect can even result in switching from centralization to decentralization as a results of an increased bias in order to make better use of the agent's private information.

\subsection{Local government as the principal}

When the local government takes the role of the principal and the federal government is the agent the local government is able to take the lead in deciding the level of centralization by taking advantage of its agenda-setting power. Like the federal government in the case described above, the local government chooses whether or not to delegate policies. Any divergence of the implemented policy $p$ from its optimal policy $p_{L}^{*}$ results in a utility loss for the local government. The game under the decentralization scheme unfolds in analogy to the previous analysis. The local government chooses whether or not to retain its control rights over policies by comparing its ex ante expected loss under decentralization with its expected loss under centralization. The choice will then, once again, depend on the size of the conflict of interest $(B)$ and on the relative importance of the two players' informational advantage $(L, F)$.

Figure 2 depicts the choice between centralization and decentralization as a function of $L$ and $F$. The boundary level $L(F, B)$ is upward sloping, and divides the $(L, F)$ plane into two regions (centralization and decentralization) lying above the $45^{\circ}$ line. In the setup with the local government as the principal, the centralization region is now smaller than the decentralization region: the existence of the agency bias requires $F$ to be strictly greater than $L$ in order for centralization to be optimal. Even when the local government has no private information and $L$ equals zero, centralization with delegated control rights to the federal government requires $F$ to be strictly greater than zero for all $B>0$. Conversely, the local government will opt for the decentralization scheme whenever its private information is more important than that of the federal government, that is $L>F$, and $L(F, B) \leq L<F$. Due to the misalignment of interests which causes the bias $B>0$, it can still be optimal for the local government to decentralize even when its informational advantage is smaller than $F$. The loss caused by the underutilization of the federal government's informa- 
tion is compensated for by the elimination of the bias and the full utilization of its own private information. As above, the threshold level $(F, B)$ is not monotone in $B$.

\section{Insert Figure 2 here}

\subsection{Empirical Implications}

Several testable implications can be derived from the model. The main prediction of the model is that decentralization prevails when the importance of the local government's private knowledge either dominates the size of the bias or dominates the importance of the federal government's private knowledge. Centralization prevails when either the importance of the federal government's knowledge or the size of the agency bias dominates the importance of local knowledge. A higher importance of local private knowledge should be related to more, and the importance of the central government's knowledge to less decentralization.

A second important feature of the model is the presence of a non-monotonic relationship between decentralization and the misalignment of interests between the government levels, which depends on the differences between the preferences of the local and federal government. Specifically, this bias in preferences has both direct and indirect effects, which are working in the opposite direction. The reason is that the federal (local) government's informational advantage may depend not only on how relevant its knowledge is per se, but also on how valuable such information is relative to those of the local (federal) government.

In countries that lack information transparency, informational advantages are salient compared to more transparent countries. Less transparency decreases the share of 'hard' information that can easily be transferred between government levels, and increases the importance of private 'soft' knowledge. The relative share of soft to hard information also depends on the quality of the communication infrastructure. The quality of information transmission makes the existing informational asymmetry, ceteris paribus, more (or less) salient and leads to a delegation of control rights over policies. Therefore, we expect that the indirect effect prevails in intransparent environments, where the information transferred by the agent is of high value to the principal. 
Finally, we highlight that the principal can either be a federal government delegating more decisionpower to the local authority, or a local government delegating more decision-power to the federal level. This distinction across regimes is an interesting testable implication based on the theoretical considerations. For this reason, we begin our empirical application with a sample that contains all countries, but also explore the two cases where either the federal or the local government is the principal. We interact the 'bias' with the quality of 'information transmission' to disentangle the direct and the indirect effects of the bias.

On the one hand, we expect to find a positive interaction between bias and information transmission when the local government is the principal, because better information transmission reduces the salience of the federal government's information and should plausibly enhance the effect of the bias on decentralization. Put simply, the easier the local governments can access specific federal knowledge, the lower the likelihood that they are willing to delegate decision-making authority based on the importance of this knowledge. On the other hand, we would expect to find a negative (or insignificant) interaction between the two when the federal government is the principal. The reason is that better information transmission reduces the salience of local information and should weaken the effect of the bias on decentralization.

Our model helps to better explain the existing variations across countries and augments the existing literature in an important way. We do however not claim to be able to estimate causal relationships in the empirical section below. Rather, we aim to test whether the data are broadly in line with the predictions of our model.

\section{Data}

\subsection{Decentralization}

We capture expenditure decentralization by the share of sub-federal expenditures in all government expenditures, taken from the International Monetary Fund's (IMF) Government Finance 
Statistics (GFS). ${ }^{15}$ The numerator of our measure is the total expenditure of sub-federal government tiers, while the denominator is total spending by all levels of government. In federal countries we use aggregated expenditures for the state and local level to proxy for 'local' expenditures given that the data do not allow further distinction. We use data for the 1972-2010 period and a maximum of 66 countries, averaged over three-year-periods to eliminate the influence of short-term fluctuations. Among the countries in our sample, expenditure decentralization ranges between 3.6 to 64.13 percent, with an average of 27.97 percent. $^{16}$ In the following, we propose a number of proxies to measure the extent of the agency bias and the relative informational advantages of the federal and local governments.

\subsection{Variables of interest}

We focus on what we call 'informational variables'. These variables capture the impact of the bias and the importance of the country's local and federal knowledge for optimal decision-making. Some are available for most of the sample, but others only for a smaller subgroup of countries and years. We therefore run separate regressions, one for the most extensive sample, and one that contains all variables.

\subsubsection{Bias}

The conflict of interest between the federal and the local governments (agency bias) depends on the degree of externalities. As one proxy for externalities, we use the perceived risk of external conflict. The larger the risk of conflict, the more important the potential externalities from centralized foreign policy on the regions. In the presence of local decision-making the deviation from the federal government's bliss point thus increases with external conflict. We use the International Country Risk Guide's (ICRG) external risk index, and transformed the original scale so that higher values imply more external risk, on a scale of 1-12. We also include trade openness, as trading with other

\footnotetext{
${ }^{15}$ Appendix D contains the definitions and sources of the variables included in the regressions below, while we provide descriptive statistics in Appendix E.

${ }^{16}$ We fill missing data for countries of the European Union since 1990 using data from Eurostat, which follows the same accounting guidelines. We tested for significant differences between the effects of data from the two sources by inserting a binary indicator in our regressions, which turned out to be insignificant at conventional levels.
} 
countries involves negotiations about trade agreements or meetings and travel to other countries to open new markets for national companies. Both local and state policies in this area might impose externalities that they do not take account of. For example, the federal government might negotiate tariff-reductions in certain areas that benefit the country as a whole, but might increase unemployment in certain regions. Local governments' trade missions might result in competition among regions, leading to trade diversion from other regions rather than trade creation. We measure openness to trade using the sum of imports and exports as a share of GDP (from the Penn World Table 7.1). Oil production also imposes externalities (Dreher and Kreibaum 2016). Large parts of the proceeds usually accrue to the federal government, while environmental damages are born locally. This can give rise to distributional conflict between the center and the regions (Gehring and Schneider 2016). ${ }^{17}$

We include additional measures of heterogeneity to proxy for bias. Our expectation is that greater diversity of the population will, on average, imply larger differences in the policy preferences of the federal government compared to that of the local governments. Our main index for the measurement of heterogeneity is Alesina et al.'s (2003) ethnic fractionalization index. As an alternative indicator, we also consider an index of ethnic tensions, provided by the ICRG (2013). The index captures perceptions among experts, ranging between 1-12 (rescaled so that higher values indicate larger tensions). As a further potential measure of bias, we include the migrant share of the total population, taken from the World Bank (2013), as migration also increases the heterogeneity of a society, ceteris paribus.

Furthermore, we include government fractionalization, as it reflects the relative political weight of the average governing party in national policy-making, which might also be an important factor in decisions about career advancement for local politicians (Banks 2011). Low fractionalization of government parties indicates that a government consists of a small number of strong parties, that each have substantial impact on policy decisions. High fractionalization, on the other hand, is indica-

\footnotetext{
${ }^{17}$ All these sources of externalities might as well reflect the reluctance of federal politicians to devolve power to the local government for reasons related to the bias, such as interest group pressure, as outlined above.
} 
tive of a larger number of weak governing parties each of which has little influence over policies. Since the ability to influence policy makes national political office attractive, higher government fractionalization, ceteris paribus, results in less attractive career options for local politicians. Their interest might consequently be less focused on central and overall country needs, which increases the misalignment of interests across government levels. ${ }^{18}$

Finally, we also use an index of government stability, taken from the ICRG (2013). Arguably, stability of the political system is an important determinant of the politicians' career concerns. One could anticipate that local politicians take the expected lifetime of their party into account when making decisions about how much effort to invest in career advancement within the party. The higher is stability, the more attractive national office becomes, and the more local politicians take the center's and overall objectives of the country into account. Thus, higher stability should relate to a smaller bias and to interests that are more aligned. The index ranges between 1-12, with higher values indicating higher stability.

\subsubsection{Knowledge}

Knowledge variables capture the relative importance of each side's private information and can affect the degree of decentralization in both directions, depending on who is in charge of deciding about the degree of centralization in policy-making. In order to proxy this measure we rely on two alternative variables, information transmission and information transparency.

The availability of reliable information is a crucial factor in determining the delegation-decision of the respective principal. The higher the share of hard relative to soft information, the lower the risk of not being fully informed by the agent. We choose two alternative proxies for this crucial variable in our model, each with distinct advantages and disadvantages. Our main proxy is the quality of information transmission, measuring how easily the local governments can get access to the federal government's knowledge and vice versa. A higher quality makes it easier to verify information

\footnotetext{
${ }^{18}$ Of course, politicians might also switch back from the federal level to a leading position at the local level. This is for instance the case for Commissioners at the European Union, who in the past often changed backed to positions at the national level. As Gehring and Schneider (2017) document, this can also cause a deviation from federal interests which we can interpret as biased decision-making.
} 
and, therefore, to assess its relevance and importance for outcomes and decisions. Our variable information transmission uses the number of telephone lines per 100 inhabitants (World Telecommunications / ICT Indicators Database 2011), which is available for a large number of countries and years. It is meant to proxy for all kind of technological barriers to the transmission of information.

The most relevant technology clearly varies over time: While the availability of internet access or mobile phones arguably is a better proxy in more recent years, it is hardly available in the earlier years of our sample. Our variable is, however, highly correlated with a combined 'media access' variable (0.80) and a variable capturing the number of computers per capita (0.87) in those periods where both are available. ${ }^{19}$ As an alternative indicator for information availability we use information transparency from Williams (2015), with higher values indicating more transparency. It is highly correlated with information transmission (rho=0.73).

We follow Hollyer et al. (2011) and include the share of data series in the areas economic policy and debt that are missing for a particular country and year in the World Bank's World Development Indicators Database (2013), labeled as missing data. ${ }^{20}$ Higher values indicate a smaller share of missing data, implying that more information is publicly available at both the central and local level. It thus decreases the principal's dependency on the respective other level, with more information being available in cases where no delegation is chosen. ${ }^{21}$

Following a similar intuition, we use two further proxies for the importance of differences between local and federal knowledge: An indicator measuring the degree of press freedom (taken from Freedom House 2011, on a scale from 0-100), and an indicator of perceived corruption (ICRG 2013, rescaled from the original scale, ranging from 1-12). Higher values indicate more press freedom and more corruption.

\footnotetext{
${ }^{19}$ 'Media access' combines access to TV, radio, papers, and internet (taken from Banks 2011). Using the media access variable does not change our results, but substantially reduces the size of our sample.

${ }^{20}$ When we instead use the share of missing data in all categories of the World Development Indicators (2013) our results are unchanged. We also calculated the share of missing data for four main indicators only (the rate of inflation, budget balance, current account balance, domestic investment), which also did not affect our results.

${ }^{21}$ Note that the correlation between the number of telephone lines and missing data is weak, indicating that these measures account for different aspects of transparency. See Hollyer et al. (2013) for a detailed discussion of these differences. Also see Dreher et al. (2017).
} 


\subsubsection{Importance of local knowledge}

The importance of local knowledge increases with greater complexity, which we proxy using ethnic tensions, ethnic fractionalization ('heterogeneity'), and migrant share, as discussed above in the context of bias. Ethnic fractionalization relates to the existence of language barriers and cultural differences that make local information more important to the federal government. All three variables increase the dependence of the federal government on local knowledge and should, therefore, lead to more decentralization.

\subsubsection{Importance of federal knowledge}

In many countries in our sample highly skilled labor is scarce. Federal government jobs typically pay better and are held in higher regard than local government jobs. Hence, if there is a shortage of highly qualified bureaucrats, they will favor jobs with the federal government. Accordingly, a lower overall level of education reduces the capacity and quality of the local bureaucracy relative to the federal one. A higher educational quality reduces the local government's dependence on the federal's knowledge and capacity and leads to more decentralization.

The importance of the federal government's knowledge increases when external risk is more prevalent. Given that negotiations with foreign authorities are the prerogative of the federal government, its knowledge gains in importance. A greater reliance on international trade, measured by trade openness, also makes the federal government's knowledge more important. Negotiations on important trade policies-like preferential trade agreements or negotiations in the context of the World Trade Organization-fall into the realm of the federal government, which should render its knowledge relatively more important. Oil production might also be important given that the federal government's knowledge matters more in oil-rich countries, for example due to tasks like working with other governments to maintain a cartel (like the Organization of the Petroleum Exporting Countries, OPEC), or building pipelines and other large-scale national and international projects. In addition, oil companies in the bulk of oil-producing nations are often at least partly 
owned by the central government with oil revenue making up a significant part of total government revenue.

Clearly, and as outlined above, some of the variables introduced here refer to both the influence of the agency problem and the importance of federal knowledge. Since the impact of such indicators could be conflicting, the sign of the coefficient will show the net effect, that is, the impact that dominates. Appendix G shows the correlations of all variables included in the analysis. Note in particular that the correlations between the variables measuring the bias and the informational variables are low. We would again like to stress that our estimates are not necessarily causal. The variables of interest are correlated with a large number of potentially important omitted variables. Moreover, some of the indicators might be determined by changes in decentralization, giving rise to reverse causality (though this is partially mitigated by using lags of the explanatory variables). We have however no reason to expect the bias to be systematically different between countries with a federal or unitary constitution, which is a decisive distinction we aim to capture.

\section{Method and basic results}

We examine the determinants of expenditure decentralization using data for a maximum of 66 countries over the 1972-2010 period, with the respective sample size depending on the set of control variables being included. Given the lack of significant time variation in the decentralization variable we have averaged the data over three years. ${ }^{22}$ Using OLS with standard errors clustered at the country level, we estimate

$$
D_{i, t}=\alpha+\beta_{1} Z_{i, t-1}+\eta_{i}+\tau_{t}+u_{i, t}
$$

where $D_{i, t}$ represents expenditure decentralization in country $i$ at period $t$, and $Z$ is a vector containing the (lagged) explanatory variables. In addition to the variables of interest, we include a set of standard control variables. ${ }^{23}$ Finally, $\eta_{i}$ and $\tau_{t}$ are region- and period-fixed effects, respectively,

\footnotetext{
${ }^{22}$ We replicated the analysis using averages of five years. While the number of observations is substantially lower, the results hold.

${ }^{23}$ Economic control variables include (log) real per capita GDP, (log) land area (in square kilometers), (log) population, the share of the urban population in total population and a binary variable indicating whether the country is
} 
and $u_{i, t}$ is the error term. ${ }^{24}$

Table 1 presents the results, using our first proxy-information transmission. Column 1 reports the coefficients of the standard variables that are most commonly used in decentralization studies. Column 2 shows the first set of variables of interest which is available for a reasonably large number of countries and years. Column 3 includes both.

\section{Insert Table 1 here}

The results of column 1 show that decentralization increases with per capita GDP and land size, at the one-percent level of significance. To the extent that larger and richer countries are more diverse, controlling for the other variables in the regression, this is in line with the model: greater diversity increases decentralization. The size of population, urbanization, and the dummy for democracies are not significant at conventional levels.

Column 2 turns to our variables of interest. As can be seen, decentralization increases with greater heterogeneity (at the one-percent level of significance). This is in line with the model's predictions. First, greater heterogeneity makes the local government's information comparably more important, leading to decentralization. Second, it increases the agency bias. As specified above, a greater bias has both a direct and an indirect effect, making the overall impact a priori ambiguous. The direct effect is to increase the agency problem, thus reducing the local government's incentive to centralize (and vice versa). The indirect effect reduces information transmission, namely the amount of information transferred by the federal to the local government under decentralization, leading to centralization (and vice versa). On average, the direct effect seems to dominate the indirect one.

The results also show that decentralization increases with less openness to trade, better information transmission, and better educational quality, all significant at the one-percent level. The negative

a democracy. Some of these variables might also relate to our hypotheses. With rising per capita GDP—and so economic activity - the exchange of information becomes more important for the design of optimal policy. This variable is obtained from the Penn World Tables and is measured in purchasing power parities (constant 2005 prices).

${ }^{24}$ We want to use cross-sectional variation for identification in addition to within-country variation due to the limited variation in the dependent variable. The results are similar with a random effects model (Appendix $\mathrm{H}$ ). 
effect of trade openness on decentralization is intuitive. In more open economies, the importance of externalities—implying a larger bias—and the federal government's knowledge is higher, making centralization better-suited compared to more closed economies. The positive effect of educational quality is also in line with our hypothesis on the importance of federal knowledge: the larger availability of well-educated people allows local governments to recruit 'better' officials, making decentralization comparably beneficial. Oil rents and missing data are not significant at conventional levels. ${ }^{25}$ Finally, better information transmission makes any difference in knowledge between the local and the federal government less decisive and is on average related to more decentralization.

Column 3 includes the variables of interest in tandem with the control variables. Per capita GDP is no longer significant at conventional levels, and trade openness also loses its significance. Heterogeneity is significant at the five-percent level and substantively important: an increase in heterogeneity by one standard deviation increases the share of subnational expenditures by about five percent. The subnational share increases by more than eight percent with an increase of information transmission by one standard deviation. An increase of one standard deviation in educational quality increases the local share of expenditures by about five percent. All of these effects are substantial in size, significant at the five-percent level at least, and jointly explain a significant share of the variation in the dependent variable. This supports the relevance of our model.

Column 4 adds the variables that are available for a reduced sample only. Note that changes in coefficients might partly be due to changes in sample size rather than the impact of these additional variables. Overall, however, the results are similar. The exceptions are the country's land area and the quality of information transmission, which are no longer significant at conventional levels. Trade openness becomes significant (again), at the ten-percent level, with a negative coefficient.

Turning to the additional control variables, decentralization significantly increases with a larger migrant share in the population and lower risk of external conflict. The coefficients are significant

\footnotetext{
${ }^{25}$ Note that the missing data variable from Hollyer et al. (2011) remains insignificant when we omit information transmission from the regression, while the effect of information transmission is unchanged when we exclude Hollyer et al.'s indicator.
} 
at the five- and one-percent level. A larger migrant share reflects greater heterogeneity, which in turn makes more decentralization optimal. An increase in the share of migrants by one standard deviation implies an increase in decentralization by nearly seven percent. Larger risks increase the importance of federal knowledge and thereby decrease the optimal level of decentralization, given the larger role of externalities. It is also economically significant, as an increase of one standard deviation would reduce the subnational expenditure share by over nineteen percent. In summary, the evidence highlights the importance of local and federal knowledge, as well as the importance of externalities in the design of a country's degree of decentralization. Overall, the results are more in line with the model's predictions when the local governments decide on the degree of centralization.

Column 5 of Table 1 turns to the two components of the bias. In order to disentangle the countervailing effects of knowledge and bias, we add an interaction of information transmission with heterogeneity to our preferred specification in column 3. Greater heterogeneity leads to a higher optimal degree of decentralization, as local knowledge becomes more important. As can be seen, the coefficient of the interaction term is positive and significant at the one-percent level. On average, the effect of heterogeneity increases with better quality of information transmission, i.e., when the gap between federal and local knowledge is smaller. Thus, for any given bias, decentralization becomes more likely with easier availability of information, as predicted by the model when the status quo is decentralization.

\section{Insert Figure 3 here}

Turning to the second component of the interaction, the bias, note that decentralization should increase with a larger bias if the local government is the principal, and decrease otherwise. This argument, however, overlooks the fact that an increase in the bias also has the (indirect) effect of reducing the amount of communication, thus making decentralization more costly from the local government's perspective (and centralization more costly from the federal government's perspective). As outlined above, the interaction between the two allows us to differentiate between the 
direct and the indirect effects. Specifically, with the local government as principal, we expect to find that a greater bias increases centralization only when information transmission is low. The positive interaction in column 5 confirms this intuition. Figure 3 shows that the marginal effect of heterogeneity on decentralization becomes positive and significant only for high levels of information transmission. It is insignificant when information transmission is low. While these results for the overall sample seem consistent with the prediction when the local government is the principal, our model suggests that they might hide considerable heterogeneity.

\section{Who is the principal and who is the agent?}

We therefore split the sample in two sub-groups according to whether the federal or the local government is more likely to have the final say on the degree of decentralization. This allows us to test the predicted differences between the two regimes. As it is arguably hard to decide which empirical proxy is most likely to capture our theoretical notion of principals and agents, we show results using a broad range of indicators. First, we consider whether a country is federal or unitary. Classifications are available from Norris (2008) and Elazar (1995), the latter being updated by Treisman (2008). Second, we distinguish countries where the constitution explicitly grants subnational governments residual power to legislate from those where all legislative power remains with the central government (Treisman 2008). Beck et al. (2001) provide data indicating whether sub-national governments have authority over taxing, spending, or legislating. In this case, they can directly influence the degree of expenditure decentralization. Third, we divide the sample based on the fact that in some countries sub-national governments are locally elected (Treisman 2008). Direct election by voters increase the legitimacy and discretionary power of subnational governments, so that it becomes more difficult for the federal government to resist and impede changes they propose. Online Appendix I shows how individual countries are classified according to the different measures.

Ideally, we would like to test our hypotheses on the importance of who is in charge of deciding about decentralization in a model including country fixed effects. However, the noise-to-signal 
ratio with the available data is so high that the coefficients of all variables in such a model become insignificant at conventional levels. Rather than including country fixed effects, we therefore address the main reason for their presence- unobserved omitted variables that are related to the decentralization ratio-by controlling for the level of decentralization in the first period in all of the following models. Under the assumption that omitted factors only have an influence on the level and not on the change in decentralization and are time-invariant, this should mitigate a potential bias.

\section{Insert Table 2 here}

Table 2 shows the results, focusing on the interaction between bias and information. The table employs both proxies for the importance of private information: information transmission and information transparency, and the five different definitions of whether a country is federal or unitary. While the theoretical effect of heterogeneity as a proxy for bias and importance of information is ambiguous in the overall sample, our model yields clearer predictions when we take institutional differences into account. For a given level of heterogeneity, an improvement in information transmission reduces the importance of federal information, leading to more decentralization with the local government as the principal ('agenda-setter'). Facing the trade-off between loss of control and loss of information, the local government is less willing to give up part of its authority in exchange for informational gains. This should be reflected in a positive interaction between the information variable and heterogeneity. On the contrary, if the central government maintains the final decision rights, better access to information means less reliance on local information. In this case, we would expect a negative interaction. Most importantly, we want to test significant differences between the two cases, which would support the relevance of the theoretical distinction we highlight.

The results are in line with our predictions and surprisingly robust across the five indicators and both information variables. In all specifications, the interaction between heterogeneity and our proxy for information is positive and significant at least at the five-percent level in federal countries, while it is negative or not significantly different from zero in unitary countries. The number 
of observations that are classified as local or federal agenda-setter differs across indicators, but the difference between the interaction terms is significant in all regressions (tested employing a seemingly unrelated regression model, with corresponding p-values shown in the table).

\section{Insert Figure 4 here}

Insert Figure 5 here

Figures 4 and 5 illustrate the differential effects for the specification using information transmission and Elazar's (1995) classification, which results in the most equal share of federal and unitary states. Figure 4 depicts the marginal effect of better information transmission on decentralization for federal states. For low levels of information transmission, higher heterogeneity does not lead to more decentralization. Only above a certain level of information transmission does higher heterogeneity make local governments opt for more decentralization. The intuition is simple: the higher the perceived misalignment of interest, the fewer tasks local governments want to delegate to the central one. However, decentralization is also limited by the need of local governments to utilize information from the center. Thus, heterogeneity only has a positive effect on decentralization when it is sufficiently easy for the local government to independently access federal information. The opposite holds when the central government is the agenda setter. If information transmission is of poor quality, greater heterogeneity makes the central government decentralize more, arguably to cope with the increased importance of local information. When access to local information is easier, the central government—-being aware of the increased misalignment in interests-does not need to decentralize. This is in line with Figure 5, which shows the marginal effect for unitary states.

\section{Conclusions}

This paper examines the endogenous allocation of control rights in federations by explicitly relating the quality of the information supplied by local governments to the federal government (and vice 
versa) to the misalignment of interests between the two. The results show that, for a given agency bias, and when the local government decides about the degree of centralization, the informational advantage of the federal government must be strictly greater than the informational advantage of the local governments for the centralization scheme to be optimal.

We disentangle the centralization and decentralization schemes by focusing on the interaction between the agency bias and information transmission. When control rights remain with the local levels of government, and the quality of information transmission is high, the effect of the agency bias on decentralization should be higher. This is the case because local governments depend less on central information, and thus react to a larger misalignment of interests by increasing decentralization, which provides more room for deviation from the federal government's preferred policies. When control rights remain with the federal government, higher quality of information transmission means less reliance on local soft and unverifiable information. Thus, the federal government will react to a larger misalignment of interests by increasing centralization.

We test the model's implications by focusing on expenditure decentralization, relating the degree of fiscal decentralization to information transmission and the size of the bias. Controlling for country-characteristics, their economic performance, and for 'political' motivations, we find empirical results consistent with the theory. Overall, better information transmission leads to more decentralization, which is consistent with the model when the status quo is decentralization. Heterogeneity captures the importance of local knowledge and the agency bias. While greater importance of the local government's knowledge leads to more decentralization, the impact of the bias is less straightforward, as it is influenced by who has the final control rights over the degree of decentralization. In our overall sample, we find that the effect of heterogeneity on decentralization increases with better quality of information transmission. This positive interaction is in line with the case where control rights lie with local governments, but masks considerable differences between unitary and federal states.

To measure these differences, we use five distinct constitutional and statutory country characteris- 
tics to separate countries where the federal government is more likely to be the principal from those where the local governments possess more constitutional power to decide on the degree of decentralization. As predicted by our model, when the local government is the principal, an increase in the bias leads to decentralization only when the quality of information transmission is relatively high. When the federal government is the principal, the interaction is negative but insignificant. Most importantly, there are significant differences between the two regimes, which supports the importance of the mechanisms highlighted in our model.

Important policy implications arise from these findings. This holds both at the country level and for supranational institutions like the European Union, in which centralized fiscal spending is rare even among groups of nations that coordinate on many policy areas, such as the Eurozone (e.g., Simon and Valasek 2017). In the case of the EU, for example, centralization may on the one hand be too low as a consequence of the bias in objectives between the member states and the institutions of the European Union. More specifically, the allocation of control rights over policies may suboptimally remain with local governments (the member states) in certain areas, under-exploiting the knowledge of the EU institutions in the presence of a bias. On the other hand, in other areas like regional policy and investments decision-making might remain with the federal entity (European Commission) even though regional information is crucial and might only be incompletely shared.

\section{Supplementary material}

Supplementary material (the Appendix) is available online at the OUP website

\section{Acknowledgments}

We thank Paolo Balduzzi, Daniel Bochsler, Massimo Bordignon, Adi Brender, Jan Fidrmuc, Fabio Fiorillo, Ilaria Fioroni, Umberto Galmarini, Mario Jametti, Geert Langenus, Katharina Michaelowa, Andrea Presbitero, Agnese Sacchi, and Christoph Schaltegger for helpful comments and suggestions and Jamie Parsons for proof-reading. We also thank participants at the Workshop on Public Finance (Rome 2017), Bruneck Workshop on Political Economy (Bruneck 2016), Crisis, Institutions, 
and Banking Union Workshop (Berlin 2014), Royal Economic Society Annual meeting (Manchester 2014), Second Workshop on Federalism and Regional Policy (Siegen 2014), 7th Annual Conference on the Political Economy of International Organizations (Princeton 2014), Political Economy of Fiscal Policy Workshop (European Central Bank 2013), Reforming Europe Conference (Mannheim 2013), EPCS Annual Meeting (Zurich 2013), the Beyond Basic Questions Workshop (Lucerne 2013), Annual Meeting of the Italian Society for Public Economics (SIEP) (Pavia 2013), the Research Training Group Globalization and Development (Hannover 2014) and seminar participants at the University of Ancona, University of Milano Bicocca, University of Calabria, Cattolica University of Milan, LUISS University in Rome, University of Munich, University of Siena, and University of Zurich for helpful comments.

\section{References}

[1] Alesina A., I. Angeloni and F. Etro, 2005, International Unions, American Economic Review, 95: 602-615.

[2] Alesina A., A. Devleeschauwer, W. Easterly, S. Kurlat and R. Wacziarg, 2003, Fractionalization, Journal of Economic Growth 8: 155-94.

[3] Alesina, A. and E. Spolaore, 2003, The Size of Nations, MIT Press, Boston, MA.

[4] Banks, A.S. and K.A. Wilson, 2013, Cross-National Time-Series Data Archive, Databanks International, Jerusalem, Israel.

[5] Bardhan P., 2016, State and Development: The Need for a Reappraisal of the Current Literature, Journal of Economic Literature 54: 862-892.

[6] Beck, T., G. Clarke, A. Groff, P. Keefer and P. Walsh, 2001, New tools in comparative political economy: The Database of Political Institutions (updated Jan. 2013), World Bank Economic Review 15: 165-176. 
[7] Blume, L. and S. Voigt, 2011, Federalism and Decentralization-a Critical Survey of Frequently used Indicators, Constitutional Political Economy 22: 238-264.

[8] Bodman, P., K. Ford, T. Gole and A. Hodge, 2010, What Drives Fiscal Decentralisation? Further Assessing the Role of Income, Fiscal Studies 31: 373-404.

[9] Bordignon, M., P. Manasse and G. Tabellini, 2001, Optimal Regional Redistribution Under Asymmetric Information, American Economic Review 91: 709-723.

[10] Crawford, V. and J. Sobel, 1982, Strategic Information Transmission, Econometrica 50: 14311451.

[11] Dessein, W., 2002, Authority and Communication in Organizations, Review of Economic Studies 69: 811-838.

[12] Dreher, A. and M. Kreibaum, 2016, Weapons of Choice: The Effect of Natural Resources on Terror and Insurgencies, Journal of Peace Research 53: 539-553.

[13] Dreher, A., S. Langlotz and S. Marchesi, 2017, Information Transmission and Ownership Consolidation in Aid Programs, Economic Inquiry: forthcoming.

[14] Elazar, D.J., 1995, From Statism to Federalism: a Paradigm Shift, Publius 25: 5-18.

[15] Freedom House, 2011, World Press Freedom Index, available at https://rsf.org/en/ranking. Last accessed: 01-05-2017.

[16] Gehring, K. and S.A. Schneider, 2016, Regional Resources and Democratic Secessionism, ETH and University of Zurich CIS Working Paper No. 90.

[17] Gehring, K. and S.A. Schneider, 2017, Towards the Greater Good? EU Commissioners' Nationality and Budget Allocation in the European Union. American Economic Journal: Economic Policy: forthcoming.

[18] Harris, M. and A. Raviv, 2005, Allocation of Decision Making Authority, Review of Finance 9: 353-383. 
[19] Hatfield, J.W. and G. Padró i Miquel, 2012, A Political Economy Theory of Partial Decentralization, Journal of the European Economic Association, 10: 605-633.

[20] Hollyer, J.R., B.P. Rosendorff and J.R. Vreeland, 2011, Democracy and Transparency, Journal of Politics 73: 1194-1205.

[21] Hollyer, J.R., B.P. Rosendorff and J.R. Vreeland, 2013, Data Disclosure, Accountability and the Facets of Transparency, Unpublished Manuscript.

[22] Hooghe, L. and G. Marks, 2013, Beyond Federalism, Publius: The Journal of Federalism 43: 179204.

[23] ICRG (International Country Risk Guide), 2013, Country Rankings, The PRS Group, East Syracuse, N.Y., various years available at https://www.prsgroup.com/category/risk-index. Last accessed: 01-05-2017.

[24] Kessler, A., 2014, Communication in Federal Politics: Universalism, Policy Uniformity, and the Optimal Allocation of Fiscal Authority, Journal of Political Economy 122: 766-805.

[25] Kotsogiannis, C. and R. Schwager, 2008, Accountability and Fiscal Equalization, Journal of Public Economics 92: 2336-2349.

[26] Lockwood, B., 2002, Distributive Politics and the Costs of Centralization, Review of Economic Studies 69: 313-337.

[27] Lorz, O. and G. Willmann, 2005, On the Endogenous Allocation of Decision Powers in Federal Structures, Journal of Urban Economics 57: 242-257.

[28] Marchesi, S., L. Sabani and A. Dreher, 2011, Read my Lips: The Role of Information Transmission in Multilateral Reform Design, Journal of International Economics 84: 86-98.

[29] Norris, P., 2008, Driving Democracy: Do Power-Sharing Institutions Work? , Cambridge University Press, New York, N.Y.

[30] Oates, W.E., 1972, Fiscal Federalism, Harcourt Brace Jovanovich, New York, N.Y. 
[31] Riker, W.H., 1987, The Development of American Federalism, Kluwer Academic Publishers, Boston, MA.

[32] Sacchi, A. and S. Salotti, 2014, How Regional Inequality Affects Fiscal Decentralisation: Accounting for the Autonomy of Subcentral Governments, Environment and Planning C: Government and Policy 32: 144-162.

[33] Simon, J. and J.M. Valasek, 2017, Centralized Fiscal Spending by Supranational Unions, Economica 333: 78-103.

[34] Treisman, D., 2006, Explaining Fiscal Decentralisation: Geography, Colonial History, Economic Development and Political Institutions, Journal of Commonwealth and Comparative Politics 44: $289-325$.

[35] Treisman, D., 2008, Decentralization Dataset, available at http://www.sscnet.ucla.edu/ polisci/faculty/treisman/. Last accessed: 01-05-2017.

[36] International Telecommunication Union, 2011, World Telecommunications Database/ ICT Indicators Database, CD-ROM, 15th edition 2011, Geneva, Switzerland.

[37] Williams, A., 2015, A Global Index of Information Transparency and Accountability, Journal of Comparative Economics, 43: 804-824.

[38] World Bank, 2013, World Development Indicators 2013, Washington, D.C. 
Table 1: Decentralization, Bias and Knowledge, 1972 - 2010, OLS

\begin{tabular}{|c|c|c|c|c|c|c|c|c|c|c|}
\hline \multirow{2}{*}{$\begin{array}{l}\text { Dependent variable: } \\
\text { Expenditure Decentralization }\end{array}$} & \multicolumn{2}{|c|}{$(1)$} & \multicolumn{2}{|c|}{$(2)$} & \multicolumn{2}{|c|}{ (3) } & \multicolumn{2}{|c|}{$(4)$} & \multicolumn{2}{|c|}{ (5) } \\
\hline & Coef. & Std. err. & Coef. & Std. err. & Coef. & Std. err. & Coef. & Std. err. & Coef. & Std. err. \\
\hline$(\log )$ GDP & $6.55^{* * *}$ & {$[2.33]$} & & & -1.42 & {$[3.04]$} & -3.66 & {$[4.31]$} & -3.98 & {$[2.70]$} \\
\hline (log) Land Area & $3.37^{* * *}$ & [1.11] & & & $2.24^{*}$ & {$[1.21]$} & 0.64 & {$[1.41]$} & $2.35^{* *}$ & [1.09] \\
\hline (log) Population & 0.45 & {$[1.41]$} & & & 0.19 & [1.41] & 1.50 & [1.35] & 0.13 & {$[1.14]$} \\
\hline Urbanization & 0.13 & {$[0.13]$} & & & 0.00 & {$[0.11]$} & 0.14 & {$[0.12]$} & 0.01 & [0.09] \\
\hline Democracy Dummy & 2.04 & {$[2.52]$} & & & -3.90 & {$[2.59]$} & -8.41 & [5.87] & $-6.40^{* *}$ & {$[2.37]$} \\
\hline Heterogeneity & & & $0.25^{* * *}$ & {$[0.08]$} & $0.21^{* *}$ & {$[0.09]$} & $0.26^{* *}$ & {$[0.10]$} & -0.11 & [0.09] \\
\hline Trade Openness & & & $-0.10^{* * *}$ & {$[0.03]$} & -0.03 & {$[0.04]$} & $-0.10^{*}$ & {$[0.05]$} & -0.03 & {$[0.03]$} \\
\hline Oil Rents & & & 0.04 & {$[0.13]$} & -0.13 & {$[0.13]$} & -0.14 & {$[0.18]$} & 0.00 & {$[0.12]$} \\
\hline Information Transmission & & & $0.40^{* * *}$ & {$[0.13]$} & $0.49^{* *}$ & {$[0.20]$} & 0.32 & {$[0.21]$} & $0.33^{*}$ & {$[0.19]$} \\
\hline Missing data & & & -0.01 & {$[0.04]$} & -0.03 & {$[0.04]$} & -0.05 & {$[0.05]$} & -0.04 & {$[0.03]$} \\
\hline Educational Quality & & & $0.29^{* * *}$ & {$[0.08]$} & $0.24^{* *}$ & [0.09] & $0.26^{* * *}$ & {$[0.09]$} & $0.30^{* * *}$ & {$[0.08]$} \\
\hline Ethnic Tensions & & & & & & & -1.45 & {$[1.45]$} & & \\
\hline Government Stability & & & & & & & -0.53 & {$[0.68]$} & & \\
\hline Government Fractionalization & & & & & & & 0.09 & {$[0.06]$} & & \\
\hline Migrant Share & & & & & & & $0.36^{* *}$ & {$[0.17]$} & & \\
\hline Risk of External Conflicts & & & & & & & $-2.41^{* * *}$ & {$[0.71]$} & & \\
\hline Corruption & & & & & & & 2.23 & [1.67] & & \\
\hline Press Freedom & & & & & & & -0.03 & {$[0.10]$} & & \\
\hline \multicolumn{3}{|c|}{ Heterogeneity ${ }^{*}$ Information Transmission } & & & & & & & $0.01^{* * *}$ & {$[0.00]$} \\
\hline Period Dummies & Yes & & Yes & & Yes & & Yes & & Yes & \\
\hline Region Dummies & Yes & & Yes & & Yes & & Yes & & Yes & \\
\hline Adj. R-Squared & 0.43 & & 0.53 & & 0.56 & & 0.63 & & 0.60 & \\
\hline Number of Observations & 389 & & 338 & & 338 & & 225 & & 338 & \\
\hline
\end{tabular}

Notes: Standard errors (clustered at the country level) in brackets. ${ }^{*} p<0.10,{ }^{* *} p<0.05,{ }^{* * *} p<0.01$. 
Table 2: Interaction between Heterogeneity and Information, 1972 - 2010, OLS

\begin{tabular}{|c|c|c|c|c|c|c|c|c|c|c|}
\hline \multirow[t]{3}{*}{ Agenda setting government level: } & Local & & Federa & & & Local & & Federal & & \\
\hline & \multicolumn{5}{|c|}{ Information Transmission } & \multicolumn{5}{|c|}{ Information Transparency } \\
\hline & Coef. & Std. err. & Coef. & Std. err. & P-value & Coef. & Std. err. & Coef. & Std. err. & P-value \\
\hline & \multicolumn{10}{|c|}{ Federation type: Unitary or federal (Norris 2008) } \\
\hline Heterogeneity ${ }^{*}$ Information & $0.017^{* * *}$ & {$[0.004]$} & -0.002 & {$[0.002]$} & 0.000 & $0.030^{* * *}$ & {$[0.007]$} & 0.002 & {$[0.002]$} & 0.000 \\
\hline Adj. R-Squared & 0.84 & & 0.89 & & & 0.870 & & 0.89 & & \\
\hline \multirow[t]{2}{*}{ Number of observations } & 126 & & 212 & & & 119 & & 191 & & \\
\hline & \multicolumn{10}{|c|}{ "Classified as "federal" (Elazar 1995) } \\
\hline Heterogeneity*Information & $0.008^{* * *}$ & {$[0.003]$} & -0.002 & {$[0.002]$} & 0.000 & $0.017^{* * *}$ & {$[0.004]$} & 0.006 & {$[0.006]$} & 0.132 \\
\hline Adj. R-Squared & 0.88 & & 0.82 & & & 0.88 & & 0.80 & & \\
\hline \multirow[t]{2}{*}{ Number of observations } & 191 & & 147 & & & 175 & & 135 & & \\
\hline & \multicolumn{10}{|c|}{ Residual powers to legislate (Treisman 2008) } \\
\hline Heterogeneity ${ }^{*}$ Information & $0.009^{* * *}$ & [0.002] & -0.001 & [0.002] & 0.000 & $0.016^{* * *}$ & {$[0.005]$} & 0.002 & {$[0.004]$} & 0.017 \\
\hline Adj. R-Squared & 0.85 & & 0.85 & & & 0.850 & & 0.83 & & \\
\hline \multirow[t]{2}{*}{ Number of observations } & 207 & & 131 & & & 190 & & 120 & & \\
\hline & \multicolumn{10}{|c|}{ Sub-national government authority (Keefer 2013) } \\
\hline Heterogeneity ${ }^{*}$ Information & $0.006^{* * *}$ & [0.002] & -0.012 & [0.016] & 0.000 & $0.013^{* *}$ & {$[0.005]$} & -0.016 & [0.012] & 0.087 \\
\hline Adj. R-Squared & 0.82 & & 0.96 & & & 0.83 & & 0.89 & & \\
\hline \multirow[t]{2}{*}{ Number of observations } & 299 & & 39 & & & 276 & & 34 & & \\
\hline & \multicolumn{10}{|c|}{ Legislature or executive locally elected (Treisman 2008) } \\
\hline Heterogeneity ${ }^{*}$ Information & $0.009^{* * *}$ & [0.002] & -0.003 & [0.003] & 0.000 & $0.017^{* * *}$ & {$[0.006]$} & -0.004 & {$[0.004]$} & 0.001 \\
\hline Adj. R-Squared & 0.81 & & 0.93 & & & 0.82 & & 0.930 & & \\
\hline Number of observations & 265 & & 71 & & & 242 & & 66 & & \\
\hline
\end{tabular}

Notes: Interaction effect between Heterogeneity and the respective information proxy for local and federal government as agenda setters. Includes initial decentralization and control variables of column 3 in Table 1 as additional regressors. Standard errors (clustered at the country level) in brackets. ${ }^{*} \mathrm{p}<0.10,{ }^{* *} \mathrm{p}<0.05,{ }^{* *} \mathrm{p}<0.01$. The $\mathrm{p}$-value corresponds to a Wald test for significant differences between the coefficients for federal and unitary states. 


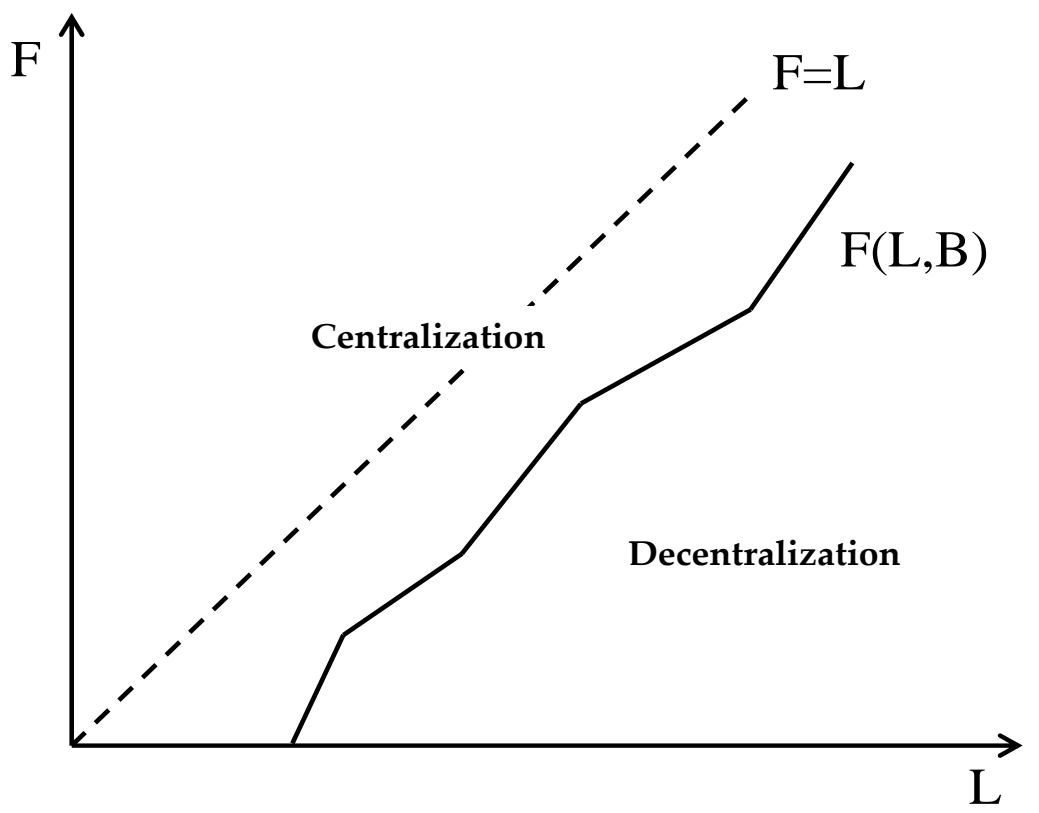

Figure 1: Choice between centralization and decentralization as a function of $L$ and $F$ when the federal government is the agenda setter

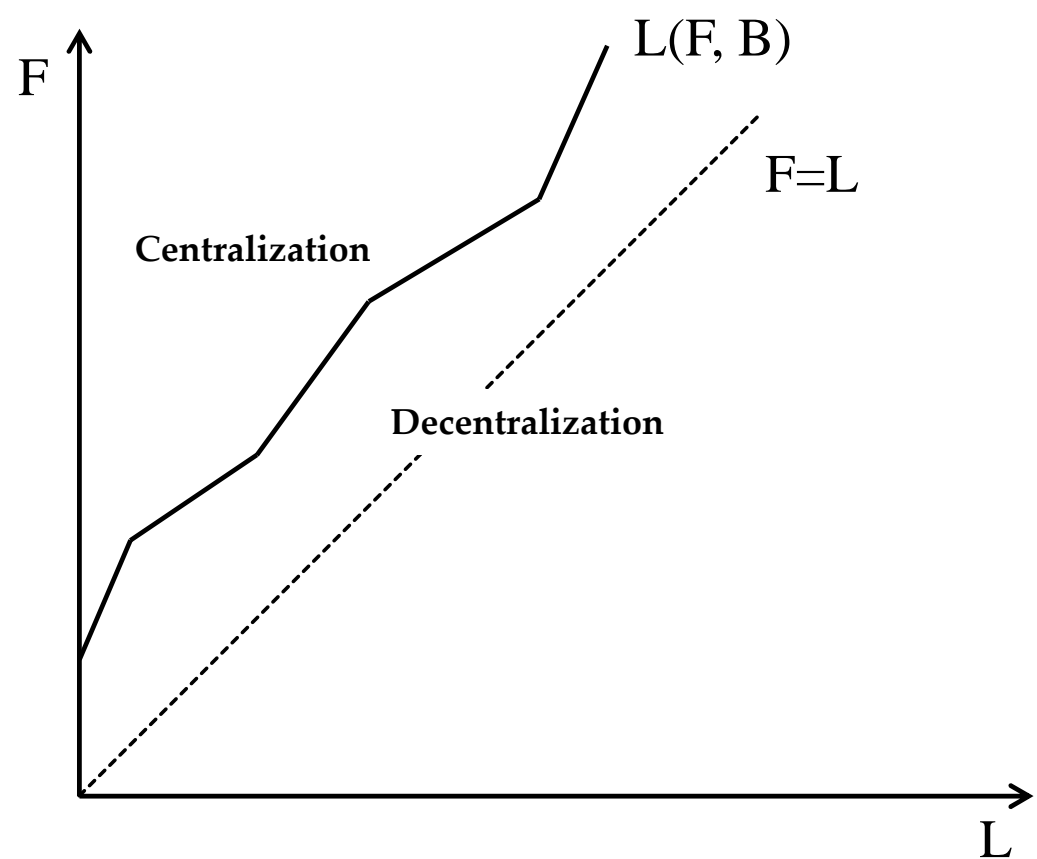

Figure 2: Choice between centralization and decentralization as a function of $\mathrm{L}$ and $\mathrm{F}$ when the local government is the agenda setter 


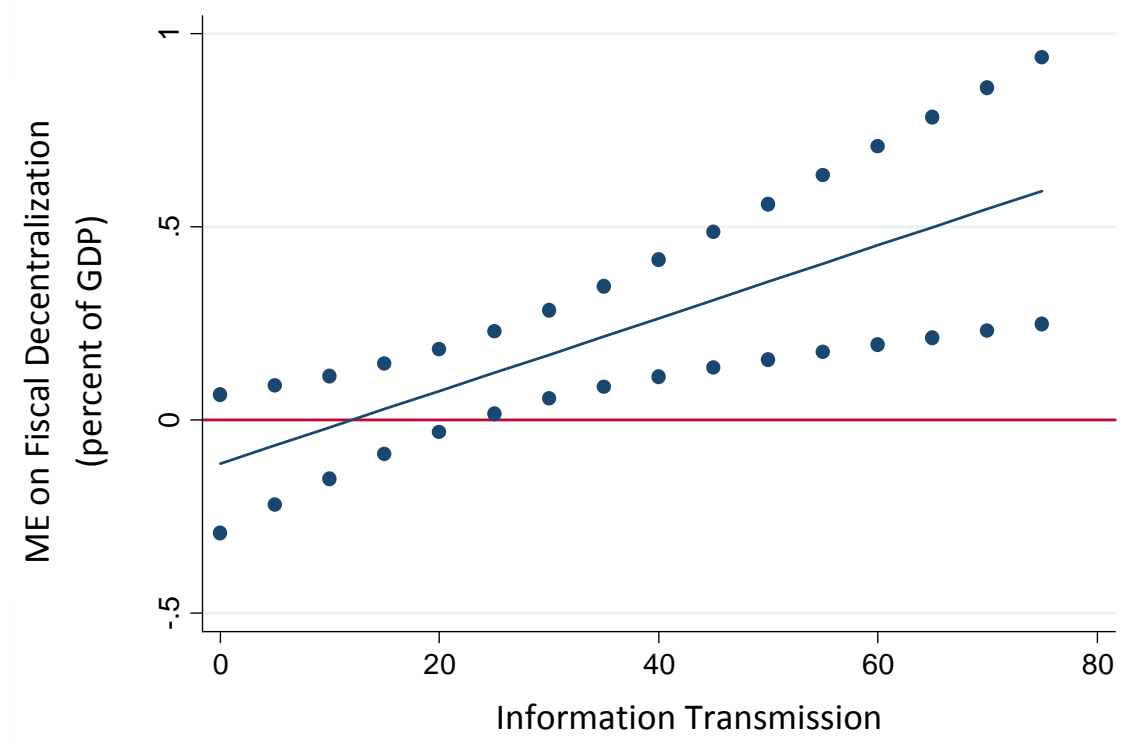

Figure 3: Marginal effect of Heterogeneity on the share of subnational government expenditure for different levels of Information Transmission (Table 1, column 5). The dashed line shows the 90\%-confidence interval.

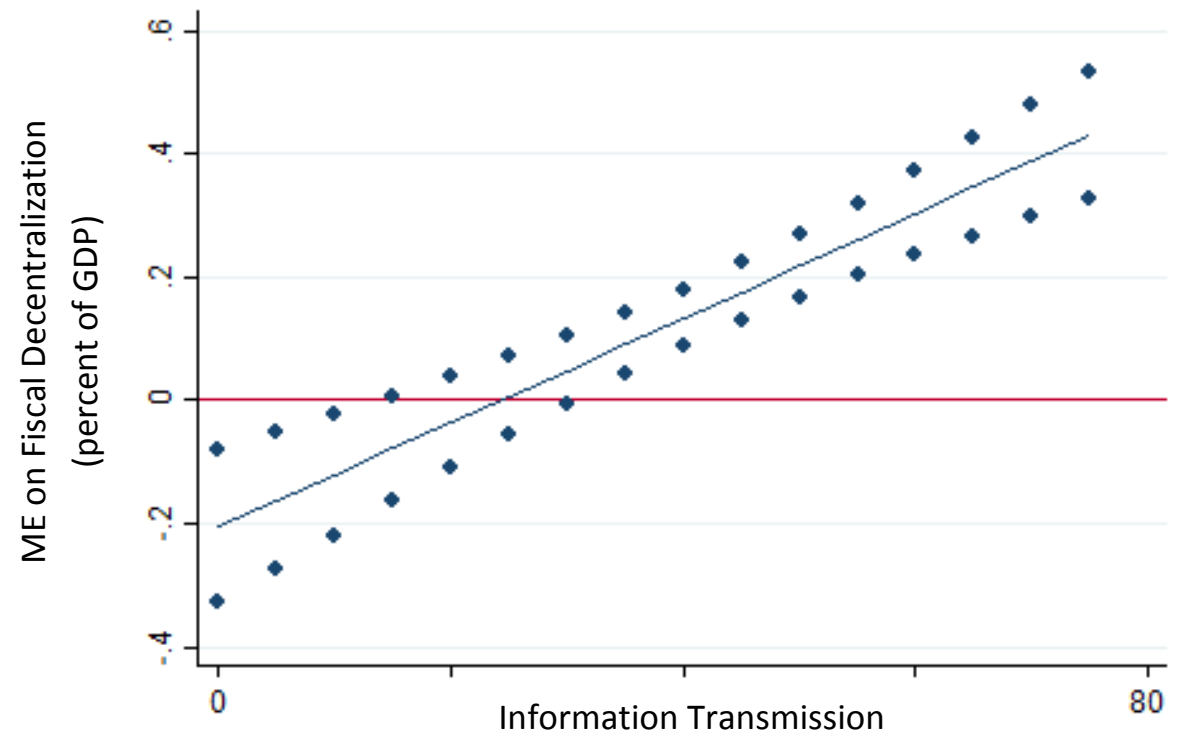

Figure 4: Marginal effect of Heterogeneity on the share of subnational government expenditure for different levels of Information Transmission (Table 2, row 2). The regressions are restricted to countries that Elazar (1995) defines as "local," i.e., where the local government is the agenda setter. The dashed line shows the $90 \%$-confidence interval. 


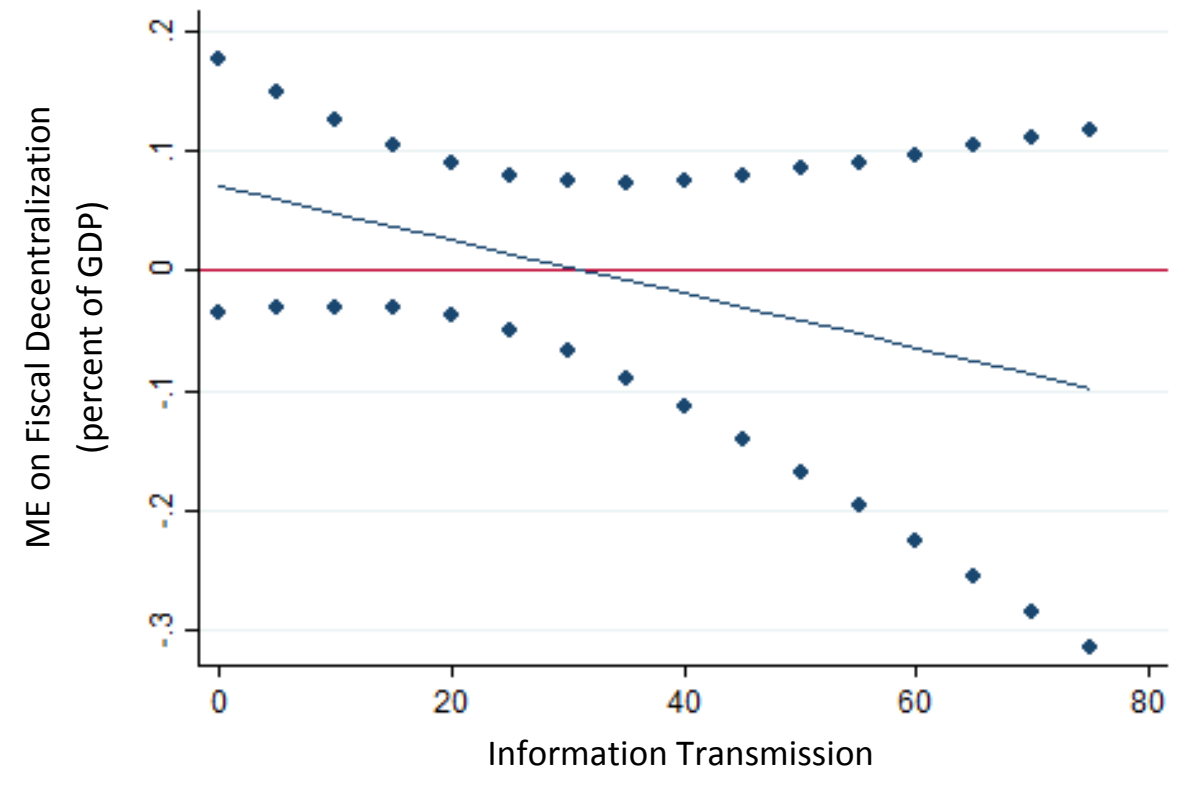

Figure 5: Marginal effect of Heterogeneity on the share of subnational government expenditure for different levels of Information Transmission (Table 2, row 2). The regressions are restricted to countries that Elazar (1995) defines as "federal," i.e., where the federal government is the agenda setter. The dashed line shows the $90 \%$-confidence interval 


\title{
Online Appendix for: Information transmission within federal fiscal architectures: theory and evidence
}

\author{
Axel Dreher ${ }^{\mathrm{a}}$, Kai Gehring ${ }^{\mathrm{b}}$, Christos Kotsogiannis ${ }^{\mathrm{c}}$ and Silvia Marchesi ${ }^{\mathrm{d}}$ \\ ${ }^{a}$ Heidelberg University; e-mail: mail@axel-dreher.de \\ bUniversity of Zurich; e-mail: mail@kai-gehring.net \\ cUniversity of Exeter; e-mail: c.kotsogiannis@exeter.ac.uk \\ ${ }^{\mathrm{d}}$ Department of Economics, University of Milano Bicocca; e-mail: \\ silvia.marchesi@unimib.it
}




\section{Appendix A: Definition and properties of the communication game}

This Appendix provides the definition of the communication game and the properties of the equilibrium outlined in Section 3.

Let $t \in[0, F]$ denote the message that the federal government sends to the local, when asked to offer its advice. Let $q(t \mid f)$ denote the density function that the federal government sends message $t$ when it has observed $f . q(t \mid f)$ is the reporting rule chosen by the federal government. Let $p(l, t)$ be the policy chosen by the local government, given the federal government has sent message $t$ to the local government. We then have:

Definition 1 A Perfect Bayesian Nash Equilibrium of the communication game consists of a reporting rule $q(t \mid f)$ and an action rule for the local government $p(l, t)$ such that:

i) for each $f \in[0, F], \int_{R} q(t \mid f) d t=1$. If $t^{*}$ is in the support of $q(t \mid f)$, $t^{*}$ is such that:

$$
t^{*}=\arg \min L^{F e d}=\int_{0}^{L}\left[p(l, t)-p_{F}^{*}\right]^{2} f_{L}(l) d l,
$$

and

ii) for each $t, p(l, t)$ solves

$$
p(l, t)=\arg \min L^{L o c}=\int_{0}^{F}\left[p(l, t)-p_{L}^{*}\right]^{2} g(f \mid t) d f,
$$

where $g(f \mid t)=\frac{q(t \mid f) f_{F}(f)}{\int_{0}^{F} q(t \mid \theta) f_{F}(\theta) d \theta}$.

According to condition $(i)$, the reporting rule $q(t \mid f)$ chosen by the federal government minimizes the federal government's expected loss, given the local government's action rule $p(l, t)$. In other words, the equilibrium reporting rule $q(t \mid f)$ induces the local government to choose policies $p(l, t)$, which minimize the expected loss of the federal government. Condition (ii) simply says that the local government responds optimally to each federal government report $t$. Namely, the local government uses Bayes' rule to update its prior on $f$, given the federal government's reporting strategy and the signal received. Then, given the federal government's report $t$ and the posterior density function of $f$ given $t$ - that is, $g(f \mid t)-p(l, t)$ minimizes the local government's expected loss. Crawford and Sobel (1982) show that this communication game does not have a full revelation equilibrium, but that there are multiple equilibria which are all partition equilibria. More specifically, the state space $[0, F]$ is partitioned into intervals and the federal government only reveals which interval the true value of $f$ belongs to. The following characterizes the relevant equilibria of the communication game.

Proposition 1 There exists at least one equilibrium with the following properties: there is a positive integer $N$, such that one can define a set of $N+1$ real numbers, with generic element denoted by $f_{i}$, such that $0=f_{0}<f_{1}<\ldots<f_{N-1}<f_{N}=1$, and

(a) $q(t \mid f)$ is uniform, supported on $\left[f_{i}, f_{i+1}\right]$, if $t \in\left(f_{i}, f_{i+1}\right)$;

(b) $p(l, t)=l+\frac{f_{i}+f_{i+1}}{2}-b_{L}$, for all $t \in\left(f_{i}, f_{i+1}\right)$.

Moreover:

(i) $\int_{0}^{L}\left[l+\left(\frac{f_{i}+f_{i+1}}{2}\right)-\left(l+f_{i}\right)-B\right]^{2} f(l) d l=\int_{0}^{L}\left[\left(l+f_{i}\right)-\left[l+\left(\frac{f_{i-1}+f_{i}}{2}\right)\right]+B\right]^{2} f(l) d l$;

(ii) $f_{0}=0 ; f_{N}=F$. 
Proof: The proof follows directly from Theorem 1 in Crawford and Sobel (1982).

Condition $(i)$ is an 'arbitrage' condition which says that for states of nature that fall on the boundaries of two intervals the federal government must be indifferent between the actions $(p(l, t))$ on these two intervals. Condition $(i)$ defines a second order linear differential equation on $f_{i}$, while condition (ii) specifies its initial and terminal conditions. Since the federal government is not informed on the true value of $l$, when choosing $t$, it will take the expected value of $l$, that is $L / 2$. The arbitrage condition $(i)$ then reduces to, for $i=1, \ldots, N-1$,

$$
\frac{L}{2}+\left(\frac{f_{i+1}+f_{i}}{2}\right)-\left(\frac{L}{2}+f_{i}\right)-B=\frac{L}{2}+f_{i}-\left[\frac{L}{2}+\left(\frac{f_{i-1}+f_{i}}{2}\right)\right]+B
$$

from which it implies

$$
f_{i+1}=2 f_{i}-f_{i-1}+4 B .
$$

This second order linear difference equation has a class of solutions parameterized by $f_{1}$ (given that $\left.f_{0}=0\right)$

$$
f_{i}=i f_{1}+2 i(i-1) B, \quad i=1, \ldots, N-1 .
$$

Given that $f_{N}=F$ it is the case that

$$
f_{1}=\frac{F-2 N(N-1) B}{N},
$$

which, using (A.4) and substituting for the value of $f_{1}$, becomes

$$
f_{i}=\frac{i F}{N}-2 i(N-i) B, \quad i=1, \ldots, N
$$

From (A.7) it follows that

$$
f_{i}-f_{i-1}=\frac{F}{N}+2(2 i-N-1) B,
$$

where the width of the interval increases by $4 B$ for each increase in $i$.

Notice that the centralization game is entirely symmetric to the decentralization game. As before, the government's report $r$ is determined by a partition $\left\{l_{i}\right\}$ of $[0, L]$. Again, it is possible to define a reporting rule $q(r \mid l)$ and a posterior belief

$$
g(l \mid r)=\frac{q(r \mid l) f_{l}(l)}{\int_{0}^{L} q(r \mid \eta) f_{L}(\eta) d(\eta)},
$$

such that, given the report $r \in\left[l_{i}, l_{i+1}\right]$, the federal's expected value of $l$ is $\left(l_{i}+l_{i+1}\right) / 2$ (posterior mean of the random variable $\widetilde{l}$, given $r$ ). Thus, the federal government will implement the following policy:

$$
p(l, r)=\frac{l_{i}+l_{i+1}}{2}+f+b_{F} \quad \text { if } \quad r \in\left[l_{i}, l_{i+1}\right], \quad i=1, \ldots, N-1 .
$$

The partition $\left\{l_{i}\right\}$ of $[0, L]$ is computed using the conditions (i) and (ii) in Proposition 1, in a similar way as above, that is:

$$
l_{N-i}-l_{N-(i-1)}=\frac{L}{N}-2(2 i-N-1) B,
$$

where the width of the interval decreases by $4 B$ for each increase in $i$. 


\section{Appendix B: Derivation of federal and local governments' ex ante expected losses}

Under decentralization, following Proposition 1 and using (A.8), the federal government's ex ante expected loss for the equilibrium of size $N$ is given by

$$
\begin{aligned}
L_{\text {Dec }}^{\text {Fed }}(N, B, F) & =\int_{0}^{F}\left(p(l, t)-p_{F}^{*}\right)^{2} g(f \mid t) d f \\
& =\int_{0}^{F}\left(l+\frac{f_{i}+f_{i+1}}{2}-b_{L}-l-f-b_{F}\right)^{2} g(f \mid t) d f \\
& =\frac{1}{F} \sum_{i=1}^{N} \int_{f_{i-1}}^{f_{i}}\left(\frac{f_{i-1}+f_{i}}{2}-f-B\right)^{2} d f \\
& =\frac{1}{F} \frac{1}{12} \sum_{i=1}^{N}\left(f_{i}-f_{i-1}\right)^{3}+\frac{1}{F} B^{2}\left(f_{0}-f_{N}\right) \\
& =\frac{1}{12} \sum_{i=1}^{N}\left[\frac{F}{N}+2(2 i-N-1) B\right]^{3}+\frac{1}{F} B^{2}\left(f_{0}-f_{N}\right), \\
& =\sigma_{f}^{2}+B^{2}\left(f_{0}=0 ; f_{N}=F, \text { see Proposition } 1\right),
\end{aligned}
$$

Here, $D$ stands for decentralization and $\sigma_{f}^{2}$ is the ex-ante residual variance of $f$, that is the uncertainty about $f$ faced by the local government before being reported by the federal government the equilibrium signal $t$, which is given by

$$
\sigma_{f}^{2} \equiv \frac{F^{2}}{12 N^{2}}+\frac{B^{2}\left(N^{2}-1\right)}{3},
$$

and it is decreasing in $N$, the expected degree of informativeness of the federal government's message.

On the other hand, the local government's ex ante expected loss is given by

$$
\begin{aligned}
L_{D e c}^{\text {Loc }}(N, B, F) & =\int_{0}^{F}\left(p(l, t)-p_{L}^{*}\right)^{2} g(f \mid t) d f \\
& =\int_{0}^{F}\left(l+\frac{f_{i}+f_{i+1}}{2}-b_{L}-l-f+b_{L}\right)^{2} g(f \mid t) d f \\
& =\frac{1}{F} \sum_{i=1}^{N} \int_{f_{i-1}}^{f_{i}}\left(\frac{f_{i-1}+f_{i}}{2}-f\right)^{2} d f \\
& =\frac{1}{12} \sum_{i=1}^{N}\left(f_{i}-f_{i-1}\right)^{3} \\
& =\frac{1}{12} \sum_{i=1}^{N}\left[\frac{F}{N}+2(2 i-N-1) B\right]^{3} \\
& =\sigma_{f}^{2}
\end{aligned}
$$

with the last equality following again from equation (B.2). Since both players' ex ante expected loss is decreasing with $N$, Crawford and Sobel assume that both agents coordinate on the most 
informative equilibrium $N(F, B)$, which is thus a focal equilibrium. ${ }^{1}$

Under centralization, following Proposition 1 and using (A.11), the federal government's ex ante expected loss for the equilibrium of size $N$ is given by:

$$
\begin{aligned}
L_{C e n}^{F e d}(N, B, F) & =\int_{0}^{L}\left[p(f, r)-p_{F}^{*}\right]^{2} g(l \mid r) d l \\
& =\frac{1}{L} \sum_{i=1}^{N} \int_{l_{i}-1}^{l_{i}}\left(\frac{l_{i}+l_{i+1}}{2}+f+b_{F}-f-l-b_{F}\right)^{2} d f \\
& =\frac{1}{L} \sum_{i=1}^{N} \int_{l_{i}-1}^{l_{i}}\left(\frac{l_{i-1}+l_{i}}{2}-l\right)^{2} d f \\
& =\frac{1}{L} \frac{1}{12} \sum_{i=1}^{N}\left(l_{i}-l_{i-1}\right)^{3} \\
& =\frac{1}{L} \frac{1}{12} \sum_{i=1}^{N}\left[\frac{L}{N}+2(2 i-N-1) B\right]^{3} \\
& =\sigma_{l}^{2}
\end{aligned}
$$

where $\sigma_{l}^{2}$ is the ex-ante residual variance of $l$, that is the uncertainty about $l$ faced by the federal government before being reported by the local government the equilibrium signal $r$, which is given by

$$
\sigma_{l}^{2} \equiv \frac{L^{2}}{12 N^{2}}+\frac{B^{2}\left(N^{2}-1\right)}{3}
$$

On the other hand, the local government's ex ante expected loss is given by

$$
\begin{aligned}
L_{C e n}^{L o c}(N, B, F) & =\int_{0}^{L}\left[p(f, r)-p_{L}^{*}\right]^{2} g(l \mid r) d l \\
& =\frac{1}{L} \sum_{i=1}^{N} \int_{l_{i}-1}^{l_{i}}\left(\frac{l_{i}+l_{i+1}}{2}+f+b_{F}-f-l+b_{L}\right)^{2} d f \\
& =\frac{1}{L} \sum_{i=1}^{N} \int_{l_{i}-1}^{l_{i}}\left(\frac{l_{i-1}+l_{i}}{2}-l+B\right)^{2} d f \\
& =\frac{1}{L} \frac{1}{12} \sum_{i=1}^{N}\left(l_{i}-l_{i-1}\right)^{3}+\frac{B^{2}}{L} \sum_{i=1}^{N}\left(l_{i}-l_{i-1}\right) \\
& =\frac{1}{L} \frac{1}{12} \sum_{i=1}^{N}\left[\frac{L}{N}+2(2 i-N-1) B\right]^{3}-\frac{B^{2}}{L}\left(l_{0}-l_{N}\right) \\
& =\sigma_{l}^{2}+B^{2}\left(l_{0}=0 ; l_{N}=L, \text { see Proposition } 1\right) .
\end{aligned}
$$

\footnotetext{
${ }^{1}$ There are, in general, multiple equilibria but, as in Crawford and Sobel (1982), one can argue that agents would reasonably coordinate on the one whose partition has the greatest number of elements. The reason is that before the sender observes her private information, this is Pareto-superior to all other equilibria.
} 


\section{Appendix C: Proof of statements in Sections 5 and 7}

The statement given in Section 5 follows directly from Proposition 2 below. By comparing its ex ante expected loss under decentralization $\left(L_{D e c}^{F e d}(N, B, F)\right)$ with the one it incurs under centralization $\left(L_{C e n}^{F e d}(N, B, F)\right)$, the federal government determines whether or not to retain its control rights over policies.

Proposition 2 The federal government prefers decentralization if and only if $L \geq F(L, B)$, where $F(L, B)$ is continuous and increasing in $L$ and, for any $B, F(L, B)<L$.

Proof: The proof follows Theorem 1 in Harris and Raviv (2005).

The statement given in Section 7 follows directly from Proposition 3 below. By comparing its ex ante expected loss under decentralization $\left(L_{D e c}^{L o c}(N, B, F)\right)$ with the one it incurs under centralization $\left(L_{C e n}^{L o c}(N, B, F)\right)$, the local government determines whether or not to retain its control rights over policies.

Proposition 3 The local government prefers centralization if and only if $F \geq L(F, B)$, where $L(F, B)$ is continuous and increasing in $F$ and, for any $B, L(F, B)>F$.

Proof: The proof follows Theorem 1 in Harris and Raviv (2005).

\section{References}

[1] Heston, A., R. Summers and B. Aten, 2012, Penn World Table Version 7.1, Center for International Comparisons of Production, Income and Prices at the University of Pennsylvania. 
Appendix D: Sources and Definitions

\begin{tabular}{|c|c|c|c|}
\hline & Variable & Definition & Source \\
\hline $\begin{array}{l}\text { DEPENDENT } \\
\text { VARIABLE }\end{array}$ & $\begin{array}{l}\text { Expenditure } \\
\text { Decentralization }\end{array}$ & $\begin{array}{l}\text { Subnational expenditures (local } \\
\text { and state level) / expenditure by } \\
\text { general government (all levels) }\end{array}$ & IMF (2012) \\
\hline \multicolumn{4}{|c|}{ CONTROL VARIABLES } \\
\hline & (log) GDP & $\begin{array}{l}\text { Log of GDP p.c., } \\
\text { purchasing power adjusted }\end{array}$ & Heston et al. (2012) \\
\hline & (log) Land Area & Log of land area (square $\mathrm{km}$ ) & Treisman (2006) \\
\hline & (log) Population & Log of population & World Bank (2013) \\
\hline & Urbanization & Urban population as $\%$ of total & World Bank (2013) \\
\hline & $\begin{array}{l}\text { Democracy } \\
\text { Dummy }\end{array}$ & $\begin{array}{l}\text { Dummy that takes the value } 1 \text { if } \\
\text { country is classified as democracy }\end{array}$ & Cheibub et al. (2010) \\
\hline
\end{tabular}

VARIABLES OF INTEREST

Bias

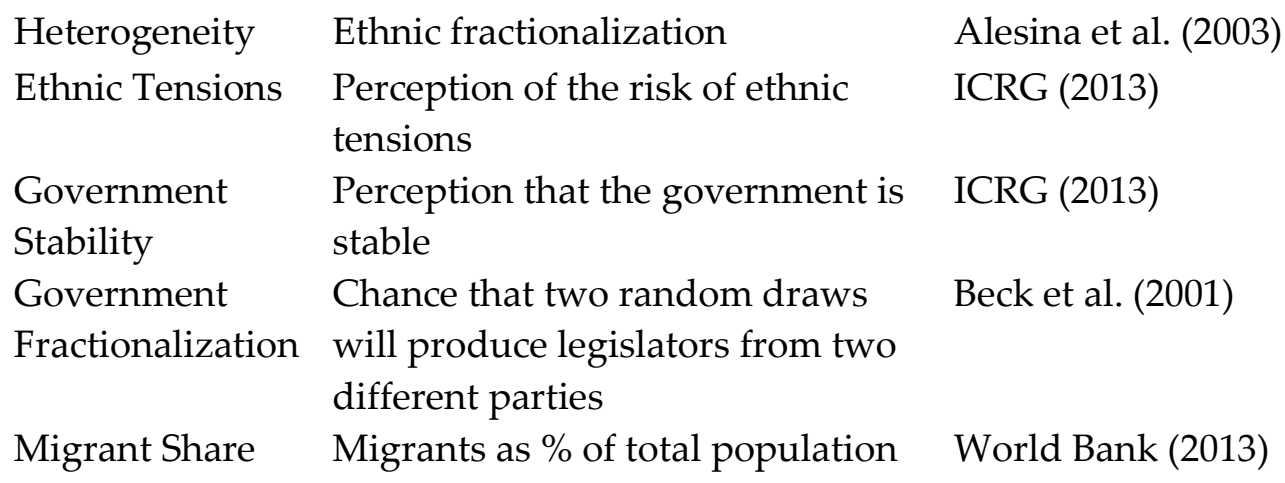

Externalities

Trade Openness Exports plus imports as \% of GDP Heston et al. (2012)

Oil Rents Oil rents (crude oil production World Bank (2013)

value at world prices minus total

production costs) as \% of GDP

Risk of External Perception of the risk of external ICRG (2013)

Conflicts conflict 
Appendix D: Sources and Definitions continued

\section{Knowledge}

\begin{tabular}{|c|c|c|}
\hline $\begin{array}{l}\text { Information } \\
\text { Transmission }\end{array}$ & $\begin{array}{l}\text { Fixed telephone lines per } 100 \\
\text { inhabitants }\end{array}$ & $\begin{array}{l}\text { International } \\
\text { Telecommunication } \\
\text { Union (2011) }\end{array}$ \\
\hline $\begin{array}{l}\text { Information } \\
\text { Transparency } \\
\text { Index }\end{array}$ & $\begin{array}{l}\text { Composite global index of } \\
\text { information transparency }\end{array}$ & Williams (2014) \\
\hline Missing data & $\begin{array}{l}\text { Share in economic policy and debt } \\
\text { indicators for which data are } \\
\text { reported }\end{array}$ & Hollyer et al. (2011) \\
\hline Corruption & Perceived corruption & ICRG (2013) \\
\hline Press Freedom & $\begin{array}{l}\text { Annual survey of media } \\
\text { independence }\end{array}$ & Freedom House (2011) \\
\hline
\end{tabular}

Importance of local knowledge

$\begin{array}{lll}\text { Heterogeneity } & \text { Ethnic fractionalization } & \text { Alesina et al. (2003) } \\ \text { Ethnic Tensions } & \begin{array}{l}\text { Perception of the risk of ethnic } \\ \text { tensions }\end{array} & \text { ICRG (2013) } \\ \text { Migrant Share } & \text { Migrants as \% of total population } & \text { World Bank (2013) }\end{array}$

\section{Importance of federal knowledge}

Educational Tertiary school enrollment as \% of the World Bank (2013)

Quality age group that officially corresponds to this level of education

Trade Openness Exports plus imports as \% of GDP Heston et al. (2012)

Oil Rents Oil rents (crude oil production value World Bank (2013) at world prices minus total production costs) as \% of GDP

Risk of External Perception of the risk of external

ICRG (2013) Conflicts conflict 


\section{Appendix E: Descriptive Statistics}

\begin{tabular}{lccccc} 
& & & Standard & \\
& Observations & Mean & Deviation & Min & Max \\
\hline Exp. Decentralization & 338 & 27.5 & 15.15 & 0.61 & 63.77 \\
$(\log )$ GDP & 338 & 9.66 & 0.82 & 6.51 & 11.24 \\
$(\log )$ Land Area & 338 & 11.82 & 1.93 & 5.77 & 16.61 \\
$(\log )$ Population & 338 & 15.97 & 1.46 & 12.30 & 19.42 \\
Urbanization & 338 & 70.19 & 14.62 & 20.02 & 97.38 \\
Democracy Dummy & 338 & 0.89 & 0.31 & 0.00 & 1.00 \\
Heterogeneity & 338 & 28.8 & 21.82 & 0.20 & 87.47 \\
Trade Openness & 338 & 80.5 & 46.51 & 14.92 & 314.71 \\
Oil Rents & 338 & 1.81 & 6.84 & 0.00 & 63.98 \\
Information Transmission & 338 & 35.53 & 17.27 & 0.15 & 72.91 \\
Information Transparency & 310 & 68.55 & 9.19 & 28 & 85 \\
Index & 338 & 20.64 & 31.8 & 0.00 & 91.12 \\
Missing data & 338 & 39.81 & 20.18 & 1.14 & 97.69 \\
Educational Quality & 279 & 1.38 & 1.14 & 0.00 & 4.92 \\
Ethnic Tensions & 279 & 8.2 & 1.58 & 3.94 & 11.42 \\
Government Stability & 279 & 66.21 & 18.79 & 0.00 & 89.71 \\
Gov. Fractionalization & 314 & 8.63 & 8.03 & 0.13 & 48.00 \\
Migrant Share & 279 & 1.19 & 1.37 & 0.00 & 9.00 \\
Risk of External Conflicts & 298 & 3.97 & 1.44 & 1.00 & 6.00 \\
Corruption & 324 & 70.98 & 18.03 & 10.67 & 95.00 \\
Press Freedom & & & & &
\end{tabular}

Notes: Descriptive statistics for all variables included in the empirical section. 
Appendix F: Decentralization, Bias and Knowledge, 1972 - 2010, OLS, Alternative knowledge proxy

\begin{tabular}{|c|c|c|c|c|c|c|c|c|c|c|}
\hline \multirow{2}{*}{$\begin{array}{l}\text { Dependent variable: } \\
\text { Expenditure Decentralization }\end{array}$} & \multicolumn{2}{|c|}{ (1) } & \multicolumn{2}{|c|}{$(2)$} & \multicolumn{2}{|c|}{ (3) } & \multicolumn{2}{|c|}{$(4)$} & \multicolumn{2}{|c|}{ (5) } \\
\hline & Coef. & Std. err. & Coef. & Std. err. & Coef. & Std. err. & Coef. & Std. err. & Coef. & Std. err. \\
\hline (log) GDP & $6.55^{* * *}$ & [2.33] & & & $6.14 *$ & [3.56] & -0.06 & [3.20] & $6.03 *$ & [3.50] \\
\hline (log) Land Area & $3.37^{* * *}$ & [1.11] & & & 2.42 & {$[1.74]$} & 0.64 & [1.88] & 2.49 & [1.70] \\
\hline (log) Population & 0.45 & [1.41] & & & -0.76 & [1.62] & 1.50 & [1.58] & -0.29 & [1.55] \\
\hline Urbanization & 0.13 & {$[0.13]$} & & & 0.08 & {$[0.13]$} & $0.24 *$ & {$[0.13]$} & 0.06 & {$[0.13]$} \\
\hline Democracy Dummy & 2.04 & [2.52] & & & -1.22 & [2.41] & -6.93 & {$[4.85]$} & -2.32 & [2.65] \\
\hline Heterogeneity & & & $0.20 *$ & {$[0.12]$} & 0.20 & {$[0.13]$} & $0.24 * *$ & {$[0.11]$} & -0.67 & {$[0.41]$} \\
\hline Trade Openness & & & $-0.08^{* *}$ & {$[0.03]$} & -0.06 & {$[0.06]$} & -0.11 & {$[0.07]$} & -0.05 & {$[0.06]$} \\
\hline Oil Rents & & & 0.25 & {$[0.17]$} & -0.11 & {$[0.18]$} & 0.02 & {$[0.27]$} & -0.03 & {$[0.18]$} \\
\hline Information Transparency & & & 0.19 & {$[0.25]$} & 0.09 & {$[0.32]$} & -0.09 & {$[0.33]$} & -0.36 & {$[0.40]$} \\
\hline Missing data & & & $-0.08^{*}$ & {$[0.04]$} & 0.00 & {$[0.04]$} & -0.01 & {$[0.05]$} & -0.02 & {$[0.05]$} \\
\hline Educational Quality & & & $0.35^{* * *}$ & {$[0.12]$} & 0.22 & {$[0.14]$} & $0.25 * *$ & {$[0.12]$} & 0.23 & {$[0.14]$} \\
\hline Ethnic Tensions & & & & & & & -2.12 & [1.32] & & \\
\hline Government Stability & & & & & & & -0.18 & {$[0.72]$} & & \\
\hline Government Fractionalization & & & & & & & 0.11 & {$[0.09]$} & & \\
\hline Migrant Share & & & & & & & $0.45^{* *}$ & {$[0.21]$} & & \\
\hline Risk of External Conflicts & & & & & & & $-2.43 * * *$ & {$[0.75]$} & & \\
\hline Corruption & & & & & & & 2.74 & {$[1.70]$} & & \\
\hline Press Freedom & & & & & & & 0.07 & {$[0.11]$} & & \\
\hline \multicolumn{3}{|c|}{ Heterogeneity* Information Transparency } & & & & & & & $0.01^{* * *}$ & {$[0.01]$} \\
\hline Period Dummies & Yes & & Yes & & Yes & & Yes & & Yes & \\
\hline Region Dummies & Yes & & Yes & & Yes & & Yes & & Yes & \\
\hline Adj. R-Squared & 0.43 & & 0.44 & & 0.49 & & 0.62 & & 0.51 & \\
\hline Number of Observations & 389 & & 310 & & 310 & & 222 & & 310 & \\
\hline
\end{tabular}

Notes: Standard errors (clustered at the country level) in brackets. ${ }^{*} \mathrm{p}<0.10,{ }^{* *} \mathrm{p}<0.05,{ }^{* * *} \mathrm{p}<0.01$. 


\section{Appendix G: Correlations}

\begin{tabular}{llllllllllllllllllll}
$(1)$ & $(2)$ & $(3)$ & $(4)$ & $(5)$ & $(6)$ & $(7)$ & $(8)$ & $(9)$ & $(10)$ & $(11)$ & $(12)$ & $(13)$ & $(14)$ & $(15)$ & $(16)$ & $(17)$ & $(18)$ & $(19)$ & $(20)$ \\
\hline
\end{tabular}

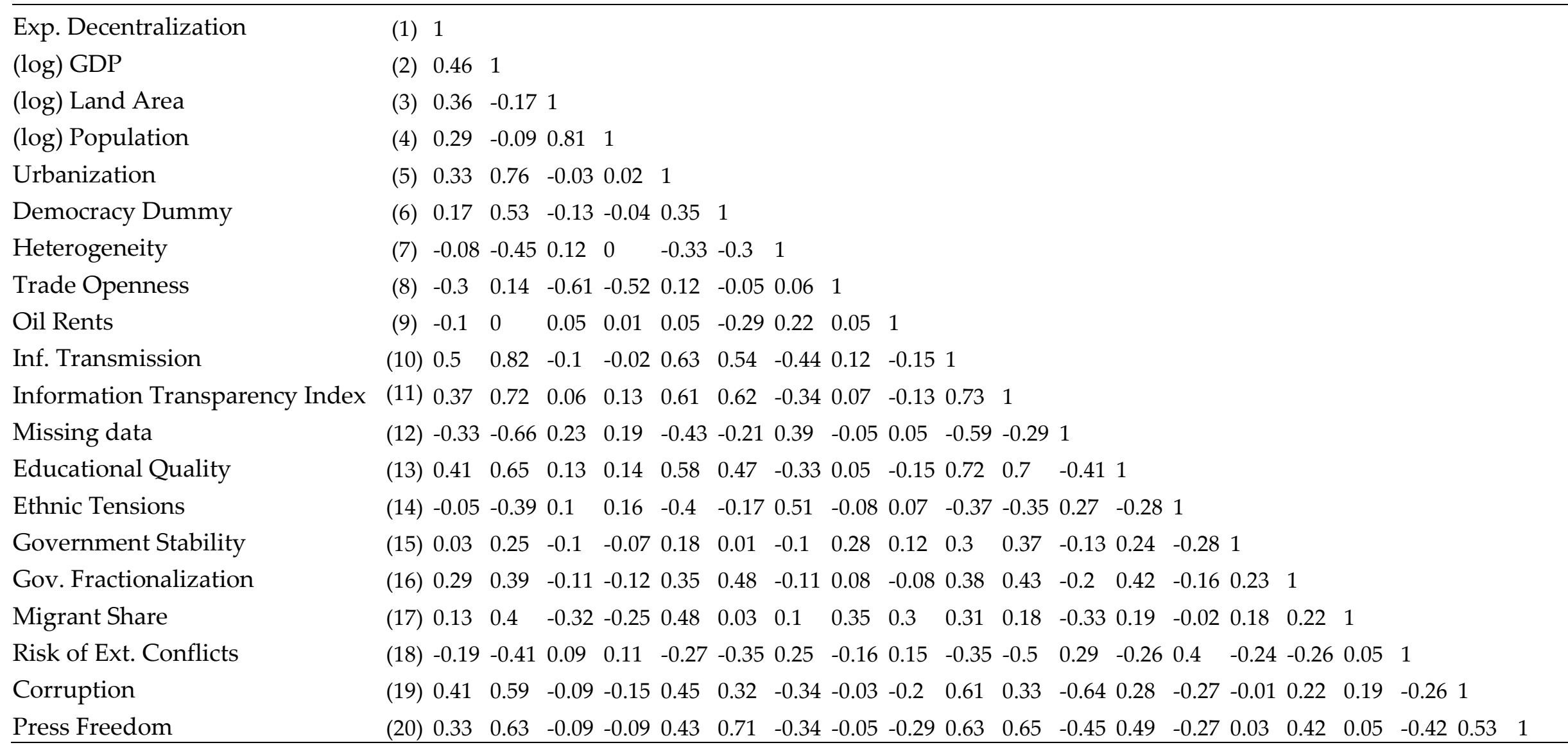

Notes: Simple correlations between all variables included in the empirical section. 
Appendix H: Decentralization, Bias and Knowledge, 1972 - 2010, Random Effects

\begin{tabular}{|c|c|c|c|c|c|c|c|c|c|c|}
\hline \multirow{2}{*}{$\begin{array}{l}\text { Dependent variable: } \\
\text { Expenditure Decentralization }\end{array}$} & \multicolumn{2}{|c|}{ (1) } & \multicolumn{2}{|c|}{ (2) } & \multicolumn{2}{|c|}{ (3) } & \multicolumn{2}{|c|}{$(4)$} & \multicolumn{2}{|c|}{ (5) } \\
\hline & Coef. & Std. err. & Coef. & Std. err. & Coef. & Std. err. & Coef. & Std. err. & Coef. & Std. err. \\
\hline (log) GDP & $4.48^{* *}$ & [1.79] & & & 2.81 & [1.89] & 2.23 & {$[2.60]$} & 0.99 & [2.13] \\
\hline (log) Land Area & $3.36^{* * *}$ & [0.97] & & & $3.69^{* * *}$ & [1.11] & $3.67^{* * *}$ & {$[1.26]$} & $4.32^{* * *}$ & {$[1.15]$} \\
\hline (log) Population & 0.68 & [1.29] & & & 0.04 & [1.29] & 1.00 & [1.69] & 0.00 & [1.25] \\
\hline Urbanization & 0.15 & {$[0.10]$} & & & $0.15^{*}$ & {$[0.08]$} & $0.20^{*}$ & {$[0.11]$} & 0.09 & {$[0.10]$} \\
\hline Democracy Dummy & 2.62 & [2.09] & & & 1.58 & [2.51] & -4.16 & [4.87] & 1.17 & [2.10] \\
\hline Heterogeneity & & & $0.12^{*}$ & {$[0.07]$} & 0.12 & {$[0.07]$} & $0.18^{* *}$ & [0.09] & -0.20 & {$[0.13]$} \\
\hline Trade Openness & & & $-0.05^{* *}$ & {$[0.02]$} & -0.02 & {$[0.03]$} & -0.02 & {$[0.04]$} & -0.02 & {$[0.02]$} \\
\hline Oil Rents & & & $-0.20^{* *}$ & [0.09] & $-0.32^{* * *}$ & [0.09] & $-0.39^{* * *}$ & {$[0.12]$} & $-0.27^{* *}$ & [0.12] \\
\hline Information Transmission & & & $0.21^{* * *}$ & {$[0.08]$} & 0.13 & {$[0.09]$} & 0.13 & {$[0.11]$} & -0.13 & {$[0.11]$} \\
\hline Missing data & & & 0.01 & {$[0.11]$} & 0.02 & {$[0.11]$} & -0.17 & {$[0.25]$} & -0.09 & {$[0.12]$} \\
\hline Educational Quality & & & $0.10^{*}$ & {$[0.06]$} & 0.06 & {$[0.06]$} & 0.03 & {$[0.06]$} & $0.12^{* *}$ & {$[0.06]$} \\
\hline Ethnic Tensions & & & & & & & -0.87 & {$[0.80]$} & & \\
\hline Government Stability & & & & & & & 0.14 & {$[0.45]$} & & \\
\hline Government Fractionalization & & & & & & & 0.05 & {$[0.07]$} & & \\
\hline Migrant Share & & & & & & & -0.03 & {$[0.38]$} & & \\
\hline Risk of External Conflicts & & & & & & & -0.38 & {$[0.63]$} & & \\
\hline Corruption & & & & & & & 0.80 & {$[0.91]$} & & \\
\hline Press Freedom & & & & & & & 0.09 & {$[0.10]$} & & \\
\hline \multicolumn{3}{|c|}{ Heterogeneity*Information Transmission } & & & & & & & $0.01^{* * *}$ & {$[0.00]$} \\
\hline Period Dummies & Yes & & Yes & & Yes & & Yes & & Yes & \\
\hline Region Dummies & Yes & & Yes & & Yes & & Yes & & Yes & \\
\hline Adj. R-Squared & 0.43 & & 0.45 & & 0.51 & & 0.58 & & 0.51 & \\
\hline Number of Observations & 389 & & 338 & & 338 & & 225 & & 338 & \\
\hline
\end{tabular}

Notes: Re-estimation of table 1 using the random-effects estimator. Standard errors (clustered at the country level) in brackets.

${ }^{*} \mathrm{p}<0.10,{ }^{* *} \mathrm{p}<0.05,{ }^{* * *} \mathrm{p}<0.01$. 
Appendix I: Classification of countries

\begin{tabular}{|c|c|c|c|c|c|c|c|c|c|c|c|c|c|c|}
\hline \multicolumn{3}{|c|}{$\begin{array}{l}\text { Federation type: } \\
\text { Unitary or federal } \\
\text { (Norris 2008) }\end{array}$} & \multicolumn{3}{|c|}{$\begin{array}{l}\text { Classified as "federal" } \\
\text { (Elazar 1995) }\end{array}$} & \multicolumn{3}{|c|}{$\begin{array}{c}\text { Residual powers to } \\
\text { legislate } \\
\text { (Treisman 2008) }\end{array}$} & \multicolumn{3}{|c|}{$\begin{array}{l}\text { Sub-national government } \\
\text { authority over taxing, } \\
\text { spending, or legislating } \\
\text { (Keefer 2013) }\end{array}$} & \multicolumn{3}{|c|}{$\begin{array}{c}\text { Legislature or } \\
\text { executive locally } \\
\text { elected } \\
\text { (Treisman 2008) }\end{array}$} \\
\hline Country & 0 & 1 & Country & 0 & 1 & Country & 0 & 1 & Country & 0 & 1 & Country & 0 & 1 \\
\hline Afghanistan & $x$ & & Albania & $X$ & & Albania & $x$ & & Argentina & & $x$ & Afghanistan & $X$ & \\
\hline Albania & $X$ & & Argentina & & $X$ & Argentina & & $X$ & Armenia & $X$ & & Albania & & $x$ \\
\hline Argentina & & $X$ & Armenia & $X$ & & Armenia & $x$ & & Australia & & $X$ & Argentina & $X$ & $x$ \\
\hline Armenia & $X$ & & Azerbaijan & $X$ & & Azerbaijan & & $X$ & Austria & & $X$ & Armenia & $X$ & $x$ \\
\hline Australia & & $X$ & Belarus & $X$ & & Belarus & $X$ & & Bahrain & $X$ & & Australia & & $x$ \\
\hline Austria & & $X$ & Bolivia & $X$ & & Bolivia & $X$ & & Belarus & $X$ & & Austria & & $x$ \\
\hline Azerbaijan & $x$ & & Botswana & $X$ & & Brazil & & $X$ & Belgium & $X$ & $x$ & Azerbaijan & $X$ & $x$ \\
\hline Bahrain & $X$ & & Brazil & & $X$ & Bulgaria & $X$ & & Bhutan & $X$ & & Bahrain & $x$ & \\
\hline Barbados & $X$ & & Bulgaria & $x$ & & Canada & & $X$ & Botswana & & $\mathrm{X}$ & Barbados & $X$ & \\
\hline Belarus & $X$ & & Canada & & $X$ & Chile & $X$ & & Brazil & & $\mathrm{X}$ & Belarus & $x$ & $x$ \\
\hline Belgium & & $X$ & Chile & $X$ & & China & $x$ & & Bulgaria & $X$ & & Belgium & & $x$ \\
\hline Bhutan & & $X$ & China & $X$ & & Colombia & $X$ & & Canada & & $x$ & Bhutan & $X$ & \\
\hline Bolivia & $x$ & & Colombia & $X$ & & Costa Rica & $x$ & & Chile & $X$ & & Bolivia & $X$ & \\
\hline Botswana & $X$ & & Costa Rica & $x$ & & Croatia & $X$ & & Colombia & & $X$ & Botswana & & $x$ \\
\hline Brazil & & $X$ & Croatia & $X$ & & Czech Republic & $X$ & & Congo, Rep. & $X$ & & Brazil & & $x$ \\
\hline Bulgaria & $x$ & & $\begin{array}{l}\text { Czech } \\
\text { Republic }\end{array}$ & $x$ & & Egypt & $x$ & & Costa Rica & $x$ & & Bulgaria & & $x$ \\
\hline Canada & & $X$ & Egypt & $X$ & & Estonia & $x$ & & Cote d'Ivoire & $X$ & & Canada & & $x$ \\
\hline Cape Verde & $X$ & & Estonia & $X$ & & Ethiopia & & $X$ & Croatia & $x$ & & Cape Verde & & $x$ \\
\hline Chile & $X$ & & Ethiopia & & $X$ & France & $X$ & & Czech Republic & & $x$ & Chile & $X$ & \\
\hline
\end{tabular}




\begin{tabular}{|c|c|c|c|c|c|c|c|c|c|c|c|c|c|}
\hline \multicolumn{14}{|c|}{ Appendix I: Classification of countries (continued) } \\
\hline China & & $x$ & France & $\mathrm{X}$ & Georgia & $X$ & & $\begin{array}{l}\text { Dominican } \\
\text { Republic }\end{array}$ & $X$ & & China & & $x$ \\
\hline Colombia & & $\mathrm{X}$ & Georgia & $X$ & Germany & & $x$ & Egypt & $X$ & $X$ & Colombia & & $X$ \\
\hline Congo, Rep. & $X$ & & Germany & $X$ & Hungary & $X$ & & Estonia & $X$ & & Congo, Rep. & & $X$ \\
\hline Costa Rica & $X$ & & Guatemala & $X$ & India & & $x$ & Ethiopia & $X$ & & Costa Rica & $X$ & \\
\hline Cote d'Ivoire & $X$ & & Hungary & $X$ & Indonesia & $X$ & & Fiji & & $X$ & Cote d'Ivoire & & $x$ \\
\hline Croatia & $x$ & & India & $X$ & Italy & & $x$ & Finland & & $X$ & Croatia & & $x$ \\
\hline Czech Republic & $X$ & & Indonesia & $X$ & Kazakhstan & $X$ & & France & $X$ & $X$ & Czech Republic & & $x$ \\
\hline Denmark & $x$ & & Italy & $X$ & Kenya & $x$ & & Georgia & $X$ & & Denmark & & $X$ \\
\hline $\begin{array}{l}\text { Dominican } \\
\text { Republic }\end{array}$ & $x$ & & Kazakhstan & $x$ & $\begin{array}{l}\text { Kyrgyz } \\
\text { Republic }\end{array}$ & $x$ & & Germany & & $X$ & $\begin{array}{l}\text { Dominican } \\
\text { Republic }\end{array}$ & $x$ & \\
\hline Egypt & $X$ & & Kenya & $x$ & Lithuania & $X$ & & Guatemala & $X$ & & Egypt & & $X$ \\
\hline Estonia & $X$ & & $\begin{array}{l}\text { Kyrgyz } \\
\text { Republic }\end{array}$ & $X$ & Malaysia & & $x$ & Hungary & $x$ & & Ethiopia & & $X$ \\
\hline Ethiopia & & $X$ & Lithuania & $x$ & Mexico & & $X$ & India & & $x$ & Fiji & & $x$ \\
\hline Fiji & & $X$ & Malaysia & $X$ & Moldova & $X$ & & Italy & & $X$ & Finland & $X$ & $x$ \\
\hline Finland & $X$ & & Mexico & $X$ & Peru & $X$ & & Kuwait & $X$ & & France & & $x$ \\
\hline France & $X$ & & Moldova & $x$ & Philippines & $X$ & & Malaysia & & $X$ & Germany & & $X$ \\
\hline Georgia & & $x$ & Nicaragua & $X$ & Poland & $X$ & & Mexico & & $x$ & Guatemala & $x$ & \\
\hline Germany & & $X$ & Panama & $X$ & Portugal & $X$ & & Philippines & & $x$ & Hungary & $X$ & \\
\hline Guatemala & $X$ & & Peru & $X$ & Romania & $X$ & & Senegal & & $X$ & Iceland & & $x$ \\
\hline Hungary & $X$ & & Philippines & $X$ & Russia & & $X$ & Singapore & $X$ & & India & & $x$ \\
\hline Iceland & $X$ & & Poland & $X$ & Senegal & $X$ & & Spain & & $X$ & Indonesia & $x$ & $x$ \\
\hline India & & $x$ & Portugal & $x$ & Singapore & $X$ & & Sweden & & $x$ & Iran & $x$ & $x$ \\
\hline Indonesia & & $x$ & Romania & $x$ & $\begin{array}{l}\text { Slovak } \\
\text { Republic }\end{array}$ & $x$ & & Switzerland & & $x$ & Ireland & & $x$ \\
\hline
\end{tabular}


Appendix I: Classification of countries (continued)

\begin{tabular}{|c|c|c|c|c|c|c|c|c|c|c|c|c|}
\hline Iran & $X$ & Russia & & X & Slovenia & $X$ & & $\begin{array}{l}\text { Trinidad and } \\
\text { Tobago }\end{array}$ & $X$ & Israel & & $x$ \\
\hline Ireland & $X$ & Senegal & $X$ & & South Africa & & $X$ & United States & $X$ & Italy & & $x$ \\
\hline Israel & $X$ & Singapore & $X$ & & Spain & & $X$ & & & Japan & & $x$ \\
\hline Italy & $X$ & $\begin{array}{l}\text { Slovak } \\
\text { Republic }\end{array}$ & $x$ & & Sweden & $X$ & & & & Jordan & $X$ & \\
\hline Jamaica & $X$ & Slovenia & $X$ & & Thailand & $X$ & & & & Kazakhstan & & $\mathrm{X}$ \\
\hline Japan & $X$ & South Africa & $x$ & & $\begin{array}{l}\text { Trinidad and } \\
\text { Tobago }\end{array}$ & $x$ & & & & Korea, Rep. & $X$ & $x$ \\
\hline Jordan & $X$ & Spain & & $X$ & Tunisia & $X$ & & & & Kuwait & $X$ & \\
\hline Kazakhstan & $x$ & Sweden & $X$ & & Uganda & $x$ & & & & Kyrgyz Republic & & $x$ \\
\hline Kenya & $X$ & Thailand & $x$ & & $\begin{array}{l}\text { United } \\
\text { Kingdom }\end{array}$ & $x$ & & & & Lesotho & $X$ & \\
\hline Korea, Rep. & $X$ & $\begin{array}{l}\text { Trinidad and } \\
\text { Tobago }\end{array}$ & $X$ & & United States & & $X$ & & & Lithuania & $X$ & \\
\hline Kuwait & $X$ & Tunisia & $x$ & & Zambia & $x$ & & & & Luxembourg & $X$ & \\
\hline $\begin{array}{l}\text { Kyrgyz } \\
\text { Republic }\end{array}$ & $X$ & Uganda & $X$ & & Zimbabwe & $x$ & & & & Macedonia & $X$ & \\
\hline Latvia & $X$ & Ukraine & $X$ & & & & & & & Malaysia & & $x$ \\
\hline Lesotho & $x$ & $\begin{array}{l}\text { United } \\
\text { Kingdom }\end{array}$ & $x$ & & & & & & & Maldives & $X$ & \\
\hline Lithuania & $X$ & United States & & $X$ & & & & & & Malta & $X$ & \\
\hline Luxembourg & $X$ & Uruguay & $X$ & & & & & & & Mauritius & & $x$ \\
\hline Macedonia & $X$ & Zambia & $X$ & & & & & & & Mexico & & $x$ \\
\hline Malaysia & $X$ & Zimbabwe & $X$ & & & & & & & Mongolia & & $x$ \\
\hline Maldives & $X$ & & & & & & & & & Netherlands & & $x$ \\
\hline
\end{tabular}


Appendix I: Classification of countries (continued)

\begin{tabular}{|c|c|c|c|c|}
\hline Malta & $X$ & New Zealand & & $X$ \\
\hline Mauritius & $X$ & Nicaragua & $X$ & \\
\hline Mexico & $X$ & Norway & & $X$ \\
\hline Moldova & $x$ & Panama & $X$ & $x$ \\
\hline Mongolia & $X$ & Paraguay & $X$ & \\
\hline Netherlands & $X$ & Peru & $X$ & \\
\hline New Zealand & $X$ & Philippines & & $X$ \\
\hline Nicaragua & $x$ & Poland & & $X$ \\
\hline Norway & $X$ & Portugal & $X$ & $x$ \\
\hline Panama & $X$ & Romania & & $X$ \\
\hline Paraguay & $x$ & Senegal & & $X$ \\
\hline Peru & $X$ & Singapore & $X$ & \\
\hline Philippines & $x$ & Slovak Republic & $X$ & $X$ \\
\hline Poland & $x$ & South Africa & & $X$ \\
\hline Portugal & $X$ & Spain & & $X$ \\
\hline Romania & $x$ & Sri Lanka & $X$ & $X$ \\
\hline Russia & $X$ & Swaziland & $X$ & \\
\hline Senegal & $x$ & Sweden & & $X$ \\
\hline Singapore & $X$ & Switzerland & & $X$ \\
\hline Slovak Republic & $X$ & Syria & $X$ & $X$ \\
\hline Slovenia & $X$ & Tajikistan & & $X$ \\
\hline South Africa & $X$ & Thailand & $X$ & \\
\hline Spain & $X$ & Togo & & $X$ \\
\hline Sri Lanka & $X$ & $\begin{array}{l}\text { Trinidad \& } \\
\text { Tobago }\end{array}$ & & $x$ \\
\hline Swaziland & $X$ & Tunisia & & $X$ \\
\hline
\end{tabular}


Appendix I: Classification of countries (continued)

\begin{tabular}{|c|c|c|c|c|}
\hline Sweden & $x$ & Uganda & $X$ & \\
\hline Switzerland & $X$ & United Kingdom & & $X$ \\
\hline Syria & $X$ & United States & & $X$ \\
\hline Tajikistan & $X$ & Uruguay & $X$ & $X$ \\
\hline Thailand & $X$ & Vietnam & $x$ & \\
\hline Togo & $X$ & Yemen, Rep. & $X$ & $X$ \\
\hline $\begin{array}{l}\text { Trinidad and } \\
\text { Tobago }\end{array}$ & $x$ & Zambia & & $x$ \\
\hline Tunisia & $x$ & Zimbabwe & $X$ & \\
\hline Uganda & $x$ & & & \\
\hline Ukraine & $X$ & & & \\
\hline United & $x$ & & & \\
\hline Kingdom & & & & \\
\hline United States & $X$ & & & \\
\hline Uruguay & $X$ & & & \\
\hline Vietnam & $X$ & & & \\
\hline Yemen, Rep. & $X$ & & & \\
\hline Zambia & $X$ & & & \\
\hline Zimbabwe & $x$ & & & \\
\hline
\end{tabular}

Notes: Classification of countries as federal or unitary. Countries where both categories are filled with an " $\mathrm{X}$ " changed within this classification during the sample period. The estimations use the classification in the respective period. For more details please refer to the original sources as provided in the references. 